Portland State University

PDXScholar

6-6-1984

\title{
The Effect on Culture-Bound Evaluation by the Intercultural Communication Workshop (ICW) at Portland State University
}

Marion Franc Sørensen

Portland State University

Follow this and additional works at: https://pdxscholar.library.pdx.edu/open_access_etds

Part of the International and Intercultural Communication Commons

Let us know how access to this document benefits you.

\section{Recommended Citation}

Sørensen, Marion Franc, "The Effect on Culture-Bound Evaluation by the Intercultural Communication Workshop (ICW) at Portland State University" (1984). Dissertations and Theses. Paper 3388. https://doi.org/10.15760/etd.5273

This Thesis is brought to you for free and open access. It has been accepted for inclusion in Dissertations and Theses by an authorized administrator of PDXScholar. Please contact us if we can make this document more accessible: pdxscholar@pdx.edu. 
AN ABSTRACT OF THE THESIS OF Marion Franc Sørensen for the Master of Science in Speech Communication presented June 6 , 1984 .

Title: The Effect on Culture-Bound Evaluation by the Intercultural Communication Workshop (ICW) at Portland State University.

APPROVED BY MEMBERS OF THE THESIS COMMITTEE:
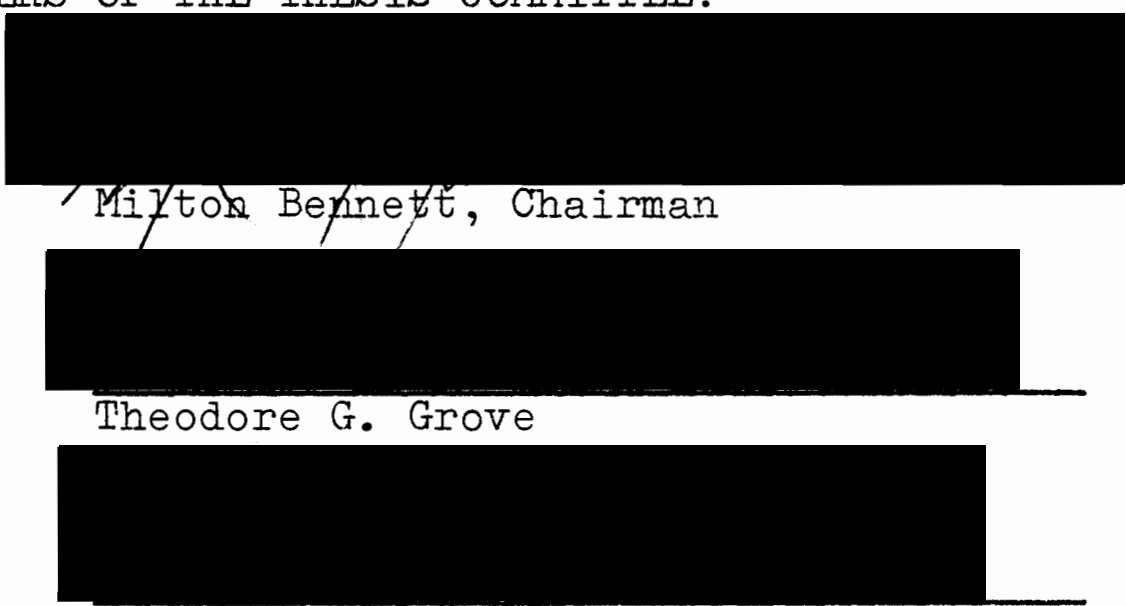

Larry Stewarc

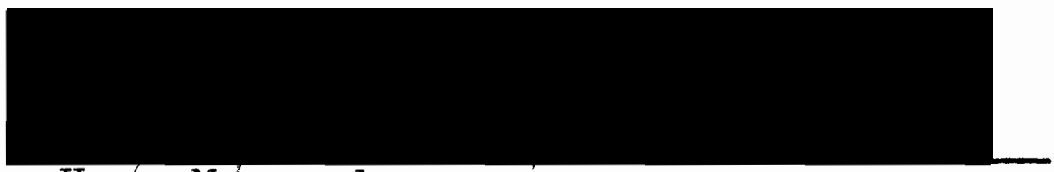

Huge Maynard

The purpose of this study is to investigate the effect on culture-bound evaluation by the intercultural Communication Workshop (ICW) at Portland State University. An increase in positive evaluation of an intercultural dyad was taken to indicate a decrease in culture-bourd evaluation. Methodology consisted of an adaptation of 
Dawes' "Direct Estimation Techniques" which was utilized in creating the testing instrument. The results are inconclusive but suggest that the ICW training may be more effective in this dimension for the American students than for International students.

Concepts from relevant literature pertaining to key communication concepts with direct application to the study are presented: the isomorphism of person perception and evaluation, the inherence of evaluation in cultural patterns, and the generally detrimental effect of culturebound evaluation on intercultural communication.

The possible alleviation of negative culture-bound evaluation through various approaches to intercultural communication and training are discussed, and the ICW's group process format is discussed in detail.

Data were collected through a testing procedure. Subjects were International and American ICW students and International and American controls. Pre- and post-data were collected. Photographs of male student dyads were shown to the subjects who were subsequently requested to complete a questionnaire.

The results were computed using a modified institutional cycle design which permitted checks on selection bias, potential testing effects, and two comparisons for hypotheses testing. 
General results proved inconclusive: hypothesis testing for ICW subjects before and after training indicated that no statistically significant differences were measured when comparing the scores on the first day of class to the scores on the last day of class. However, statistically significant differences were registered for American ICW subjects when compared with the control nonICW subjects. For International students, no statistically significant differences were indicated in comparison to the control non-ICW student peers.

These inconclusive results suggested to the investigator that perhaps the training provided by the ICW is better suited to American than International students, and reasons for these differences are discussed.

Directions for future research in intercultural communication education and training that may clarify the situation are suggested. 
THE EFFECT ON CULTURE-BOUND EVALUATION BY THE INTERCULTURAI COMIUNICATION WORKSHOP (ICW)

AT PORTLAND STATE UNIVERSITY

by

MARION FRANC SØRENSEN

A thesis submitted in partial fulfillment of the requirements for the degree of

\author{
MASTER OF SCIENCE \\ in \\ SPEECH COMIUNICATION
}

Portland State University

1984 
TO THE OFFICE OF GRADUATE STUDIES AND RESEARCH:

The members of the Committee approve the thesis of Marion Franc Sørensen presented June 6, 1984.

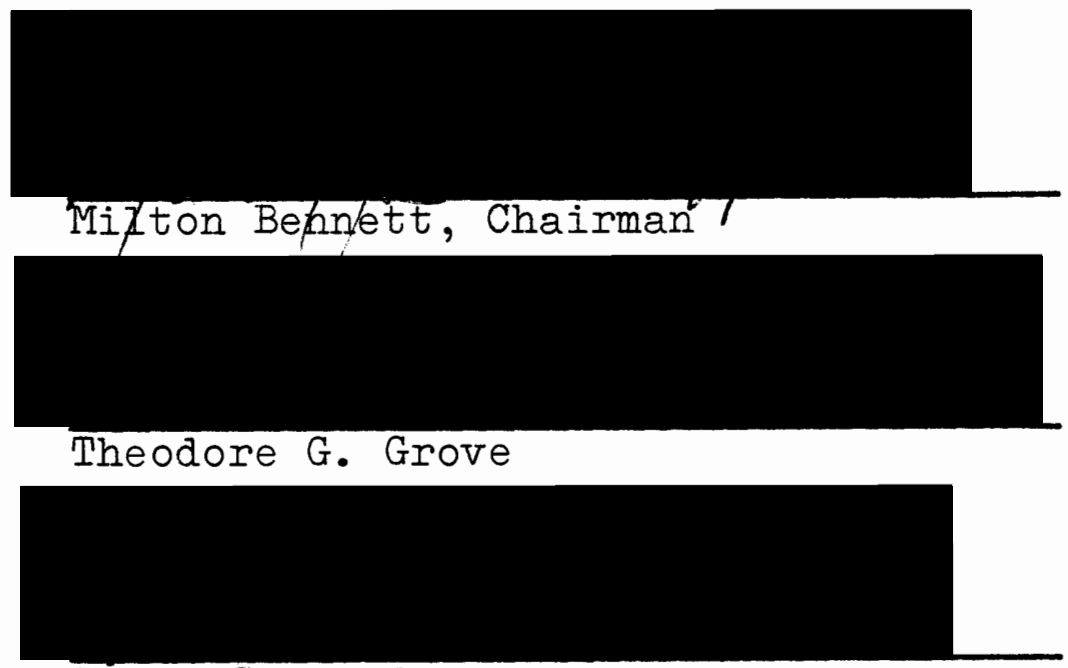

Larry Steward

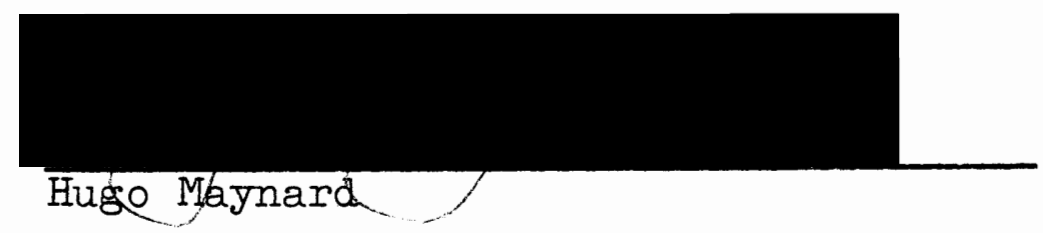

\section{APPROVED :}

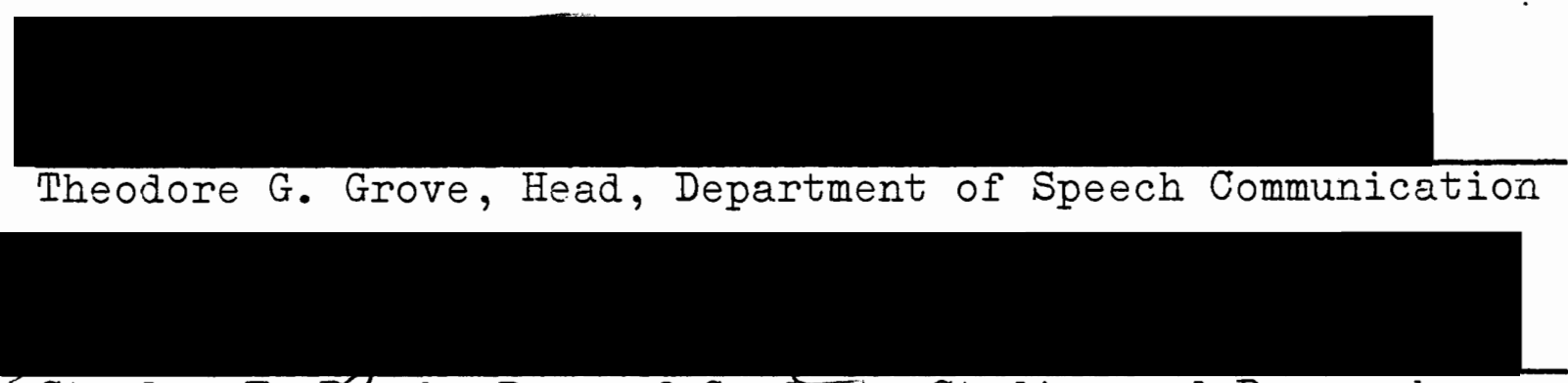

Stanley E. Rzuch, Dean of Graduate Studies and Research 


\section{ACKNOWLEDGMENTS}

Having spent my childhood and adolescence in Norway and adult years in Sweden, Canada, and the United States, it seems natural that I pursued studies in intercultural communication in college. The area soon became of special interest, particularly intercultural communication education and training. This background has been influential in writing the present study, which undertaking has been far from lonely. I have received help and encouragement from many individuals.

I am grateful to my advisor, Dr. Milton Bennett, who has had the stamina to stick with me throughout the years this study has taken; to Dr. Ted Grove for his patient assistance; to the members of my thesis committee, Dr. Larry Steward and Dr. Hugo Maynard. Without these people I would not have been able to carry out this study.

I am also exceedingly thankful for the support given by many others, and the following list is by no means complete:
LaRay Barna Gerri Davis
Germaine Kellerman
Keith Davis Virginia Lawrence Trisha Davis Lonna Liddell Kathy Fishler Joan Malling
Pat Hamilton 
Great thanks are also extended to Mrs. Barbara Vogelsang for her typing of this thesis and to Gustavo Rapoport for his photographic work. I will forever be indebted to my special friend and colleague, Jeff Sweeney, whose support and editorial guidance have been invaluable. Lastly, I wish to express my appreciation to my wonderful husband, John Franc. John's never-waivering love, understanding, and keen sense of humor ultimately made the writing of this thesis possible.

To all of you, "tusen takk" as they say in Norway. 
TABLE OF CONTENTS

PAGE

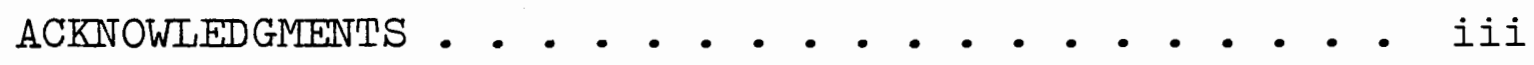

IIST OF TABLES . . . . . . . . . . . . . . viii

IIST OF FIGURES . . . . . . . . . . . . . . . $\mathrm{x}$

CHAPTER

I EVALUATION IN COMMUNICATION • . • . . . . 1

Evaluation . . . . . . . . . . 1

Person Perception and Communication . • 4

Cultural Factors and Evaluation ... 10

Evaluation as an Intercultural

Communication Problem . . . . . 15

Summary • • • • • • • • • • • • • 19

II INTERCULTURAL COMMUN ICATION EDUCATION:

NEEDS AND APPROACHES ... . . . . . . 22

What Should Be the Objectives of

Intercultural Communication

Education? .......... 23

What Learning Procedures Should Be

Used to Achieve the Educational

Objective of Intercultural

Communication Education? . . . 28

General History of Intercultural

Communication Education . . . . 30

Intercultural Communication Education

at Portland State University . . . $3 i$

The Intercultural Communication

Workshop: Students and Structure . 33 
III METHODS AND PROCEDURES . . . . . . . . 39

Hypotheses . . . . . . . . . 39

Designing the "First Impression Test" . 41

Subject Selection and Testing Procedures........... 53

The Research Design . . . . . . 59

IV RESULTS . . . . . . . . . . . 61

Design and Data Collection Summary . . 61

Selection Bias .. ..... . 62

Testing Effects ......... 65

Nonequivalent Posttest-Only .... 68

One Group Pretest-Posttest . . . . 73

Summary . . . . . . . . 77

$\mathrm{V}$ CONCLUSION ............... 80

BIBLIOGRAPHY • . • . . . • . . . . . 88 APPEND IX

A Definition of Terms . . . . . . . . 92

B Syllabus for Speech 140 (The ICW) . . . . 97

C Syllabus for Speech 507 (Intercultural Facilitation ........... 101

D First Impression Test .......... 105

E Rating Adjectives on a Seven to One Continuum ........... 108

F Scoring and Computing Adjectives . . . . 115

G Thirty Scaled Adjectives . . . . . . . 117 
$\mathrm{H}$ Correlational Study for Rating Adjectives on a Seven to One Continuum . . . . 120

I Photographs of Dyads . . . . . . . . 129

$\mathrm{J}$ Reversed Order of Adjective Lists . . . . 135 


\section{IIST OF TABIES}

TABLE

PAGE

I Analysis of Variance for Pretreatment ICW

$(n=13)$ and Control Americans $(n=50)$ on

Three Pictures . . . . . . . . .

II Analysis of Variance for Pretreatment ICW

$(n=18)$ and Control Internationals $(n=19)$

on Three Pictures ......... 64

III Means for All Subjects .. . . . . . 65

IV Analysis of Variance for Pretested $(n=13)$ and

Nonpretested $(n=20)$ ICW American

Subjects . . . . . . . . . 66

$\mathrm{V}$ Analysis of Variance for Pretested $(n=8)$ and

Nonpretested $(\mathrm{n}=18)$ International

Subjects . . . . . . . . . 67

VI Means for All Subjects . . . . . . . 68

VII T-Test for American ICW Subjects after

Training and American General Control

Subjects . . . . . . . . . . 70

VIII T-Test for International ICW Subjects after

Training and International General

Control Subjects . . . . . . . 72 
IX T-Test for ICW American Subjects, Pretest and Posttest.......... 75

X T-Test for ICW International Subjects, Pretest and Posttest . . . . . 76 


\section{IIST OF FIGURES}

FIGURE

PAGE

1 Modified Institutional Cycle Design . . . . 59

2 American/American Dyad . . . . . . . 130

3 American/Saudi Arabian Dyad . . . . . . 131

4 American/Japanese Dyad . . . . . . . 132

5 American/American Dyad . . . . . . . 133

6 American/Black Iibyan Dyad . . . . . 134 


\section{CHAPTER I}

\section{EVALUATION IN COMMUNICATION}

The purpose of this study is to investigate the effects education and training can have upon culture-bound evaluation. For purposes of this study, investigation is focused on the training and communication provided in the Intercultural Communication Workshop (ICW) offered through the Speech Communication Division at Portland State University.

In this chapter, relevant literature is reviewed. Key communication concepts which have direct application to the study are presented: the isomorphism of person perception and evaluation, the inherence of evaluation in cultural patterns, and the generally detrimental effect of culture-bound evaluation on intercultural communication.

The key communication concepts' relationship to one another and definitions of relevant terms, "evaluation," "person perception," "communication," and "cultural factors," are also discussed.

\section{EVALUATION}

Some theorists, Hastorf among them, contend that value judgments are used to categorize stimuli into structured, stable, and meaningful experiences: 
One of the ways we make sense out of the complexity is to make inferences that go beyond the behavioral data . . he selects and categorizes, he interprets and infers to achieve a meaningful world in which he can act (Hastorf et al. 1970, p. 12).

Thus, Hastorf identifies the intrapersonal processes which are involved in perception: selection of stimuli, categorization, interpretation, and inference. According to Bem (1970, p. 14), people do not have the same tendency to evaluate inanimate objects as frequently as they do other people. For example, the shapes and sizes of oranges may be a matter of indifference to those who eat them; simple judgments may be rendered as to degree of sweetness or richness of color, but it is uncommon for people to evaluate oranges compulsively, as if every orange must be classified as good or bad. Yet, as Bem points out, for every person there are some objects which are more central among beliefs. With regard to these, value judgments are nearly always rendered (Rokeach 1968, p. 170). Viewed in this way, evaluation is an outcome of these perceptual processes.

Where perception of persons is concerned, the tendency to evaluate appears to be implicit. "Person perception" refers to the process of intrapersonally taking inventory of another by selectively perceiving certain verbal and nonverbal cues. According to Hastorf (1970, pp. 12, 13, 14, 17), it is a process which includes 
evaluation at each step, from when stimuli from another are first encountered until they are coded and interpreted. The complexity of this process is not merely that it is psychological and, therefore, cannot be directly observed. It is further complicated by two important factors: at the intrapersonal level, the process can be a nonlinear, almost simultaneous occurrence which is so habitual as to be unconscious. At the interpersonal level, the ongoing interaction between communicators creates reciprocal influences of perception and behavior which can be in themselves, exceedingly complicated.

Thus, person perception is a highly subjective process of making judgments about the feelings, attitudes, and purposes of others based upon selectively perceived verbal and nonverbal cues. Whan a person perceives another, the one encountered may be internally described in terms of physical attributes. For example, account may be taken of how fat or thin, tall or short, strong or weak that person appears to be (Bem 1970, p. 14). If there is speech, vocal qualities may be attended to, and from these paralinguistic cues the person's emotional state may be inferred (Swenson 1973, p. 109). It is likely that the most significant cues will be nonverbal ones, because it is this aspect which largely determines the meaning of a message (Mehrabian 1979, p. 193). 
The notion of "cues" does not imply that person perception is always conscious; on the contrary, much of it occurs so subtly that it cannot be taken into account, even when one attempts to monitor the process (Haggard and Isaacs 1966, p. 165). For example, a woman engaged in person perception does not necessarily communicate intrapersonally that she is liking another because of his or her cleanliness, pleasant smile, attractive eye color, or trustworthy tone of voice. Even if she recognizes her reaction to some of these stimuli, many of her perceptions are gathered and interpreted subliminally (Bateson 1980, p. 34). The process may be unconscious, but the resulting judgment will often be recognized.

Evaluativeness in the person perception process is often exacerbated by the interactive nature of interpersonal communication. As each communicator gathers sense data and concurrently interprets and responds to it, personal impressions are formed and changed in an ongoing reciprocal manner (Hopper and Whitehead 1979, p. 34; Ruesch and Bateson 1968, p. 207). Thus, even in the safest, most casual modes of communication, and regardless of the complexity of the situation, the process of person perception will result in an evaluative response.

\section{PERSON PERCEPTION AND COMIUNICATION}

In order to understand how evaluation constitutes an issue in intercultural communication, it may be helpful 
to review the role it plays in the context of the general communication process.

Person perception and evaluation are fundamental acts of intrapersonal communication:

Whenever activities of an organ or of the whole organism are perceived by the self or others, they constitute communicative acts which warrant interpretation. The higher centers of the nervous system and perhaps certain glands evaluate messages originating in single organs, and a person may respond automatically, sometimes not being consciously aware of this transmission. . . In transmission of messages from person to person information pertaining to the state of the organism of the speakers is frequently transmitted without awareness of the participants. In social situations, for example, people automatically evaluate the other's attitude--that is, whether it is friendly or hostile (Ruesch and Bateson 1968, p. 31).

These operations are thus related: the gathering of sense data, their interpretation and evaluation make up a behavior chain--the perceptual process--which is itself an intrapersonal communicative act. Therefore, in this study, the term "communication process" is assumed to include the previously described person perception process.

The theoretical connection between communication and perception is widely discussed in communication literature. ${ }^{1}$ The practical significance of the connection between person perception and communication is supported by the inclusion of authors of speech communication textbooks of exercises in interpersonal "judgment." A typical example is an exercise called "Personal Evaluation" found in an introductory speech communication textbook, Communication Concepts and Skills, by Robert Hopper and Jack L. Whitehead 
(1979, p. 31). The exercise consists of eliciting from students their judgments of selected persons according to six categories, each consisting of paired terms along a continuum: active/passive, trustworthy/untrustworthy, knowledgeable/uninformed, good/bad, warm/cold, and strong/ weak. Many students find it quite easy to make these kinds of judgments, particularly about people they know well and media personalities. Yet, these students are often unaware, before the exercise, of having made such judgments. Thus, the "Personal Evaluation" exercise helps students to recognize that the judgments that they make of others are an aspect of their habitual communication behavior; that is, such behavior does commonly occur without the students paying any attention to an evaluation taking place.

As has been suggested above, evaluations of people and circumstances do occur commonly; they are ordinary communication behavior. This is not to suggest that they occur arbitrarily or without justification, since one's personal safety and livelihood may depend upon the ability to make sound judgments of, for example, the intentions of others. Thus, evaluation is requisite in the intrapersonal communication process of abstracting. However, not all evaluation is "effective," that is, facilitative of successful communication. Communicative success, as defined here, is that which is based upon an appropriate assumption of similarity (Bennett 1979). 
It has been noted that human communication behavior is marked by an "isomorphic" tendency--the assumption that there exists among communicants certain common characteristics (Maslow 1967, p. 195). Hastorf (1970, p. 15) states: "We behave, think, feel, and some of the structured meanings we experience derive from the assumption that other people are like us." In intracultural communication, this assumption of similarity serves as a normative description, the context for person perception and a source of criteria for success. However, judgments based on this assumption may be inappropriate in situations where either difference or change may be encountered; such cases are typical in intercultural communication.

When dissimilarity is encountered in communication, whether or not the situation is intercultural, inappropriate evaluation can create communication problems--from minor misunderstandings to dangerously threatening situations. Communication itself may appear threatening. According to Barnlund, communication nearly always contains an element of change--and change may be perceived as most threatening:

Aside from common social rituals, men nearly always talk in a context of change. What prompts the communication is the desire for someone to see our facts, appreciate our values, share our feelings, accept our decisions. Communication is initiated, consciously or unconsciously, to change the other person. If difference is the raw material of conversation, influence is its intent (Barnlund 1979, p. 10). 
In this vein, communication takes place within the context of change with the intent to influence. In everyday conversation, this intent to influence may be mostly unconscious, but when further reflected upon, even the most casual chatter is intended to obtain agreement or, at the least, appreciation for the viewpoints expressed. People are commonly involved in communication behavior which aims at social reinforcement for one's perceptions or, at least, an avoidance of change (Sherif 1967).

If change is perceived as threatening, then resistance to change must be a fact of life in communication (Marris 1975, p. 7). Resistance to change differs in magnitude according to how attached a person feels to that which must be relinquished:

To change is to give up cherished values, to be left defenseless and forced to assume responsibility for a new organization of experience. The degree to which fear is aroused is usually proportional to the extent to which core values are placed in question (Barnlund 1979, p. 10).

It can be most painful to abandon values passed down through generations, assumptions taken for granted during a lifetime, or revered beliefs, in order to organize experience in new ways. It is understandable, then, that such situations will elicit feelings of threat or fear; the resistance to change one is likely to experience to be directly proportional to the depth or centrality of the values, assumptions, and beliefs which one risks to change. 
What happens to the communication process when one, both, or all parties to an interaction feel threatened or defensive? For one thing, more energy is likely to be expended in defense against change than in engaging in the communicative tasks at hand. For example, one may become concerned with how one is perceived by others and how it may be possible to be perceived more favorably (Gibb 1979, p. 202). Since person perception is an interactive process, defense in one person will tend to create a similar defensiveness in others. Through this mirroring effect, increasing evaluation leads to accelerating defensiveness (Gibb 1979, p. 202). Barnlund (1979) states that highly evaluative communication situations are among the most threatening experiences a person may encounter:

The most familiar form of threat is found in a highly evaluative communication context. There is continual appraisal. Remarks are judged rather than understood. Conversation becomes crossexamination. Criticism may be given directly through attack or indirectly through sarcasm or innuendo (p. 13).

Clearly, the threatening aspects of being evaluated are not conducive to successful communication, but it is no more possible to cease evaluating than it is to stop perceiving people; the processes are intrinsically linked. Thus, if to evaluate is an integral part of being human, then so are the corresponding perceptions of threat and defensiveness.

So far in this chapter, it has been argued that evaluation is a normal outcome of human perception and, in 
interpersonal communication, an inherent stage in ordinary processes of person perception. Further, while evaluation is requisite in communication, not all evaluation facilitates communicative success. In particular, because evaluative responses tend to increase the level of perceived threat in communication situations, they can be the source of difficulties in communication. Such difficulties are more likely to develop, and be more significant in situations where differences among communicators are encountered. Finally, it has been mentioned that the most potent sources of evaluation are deeply held values, beliefs, and attitudes. Continuing with this line of reasoning, the next section considers the relationship of cultural factors and evaluation.

\section{CULTURAI FACTORS AND EVALUATION}

In this section, the term "culture" is defined and its relationship to evaluation considered. Consideration of cultural factors is most important because this investigation is concerned with the effect of a particular kind of communication training and the tendency towards culturebound evaluation in situations where cultures are clearly different.

Over the past eighty years, theorists have proposed various and divergent definitions for the term "culture." 2 Many of these definitions are drawn from the literature of 
anthropology, sociology, and communication, and are interesting and appropriate for their original context; yet within the comparatively young field of intercultural communication, no single definition of "culture" appears to have gained general acceptance among writers. For this reason, and because of the specific focus of this study, a definition has been selected which emphasizes how culture is transmitted across generations--a process known generally as "socialization" (Brislin 1981, p. 23).

For the purposes of this study, the term "culture" shall be broady defined as a complex whole consisting of the sum of knowledge and behavioral patterns acquired by members of a specific society (Tyles 1881, p. 4). By knowledge is meant the cumulative deposit of ideas passed down through generations; experiences, meanings, beliefs, values, and attitudes. 3 "Behavioral patterns" refer to the effects of culture as a template for the relationship one has with nature and the universe, others, and oneself. Significantly, culture is here conceived as an inherent and substantial feature of human behavior, particularly communicative behavior which dictates how status hierarchies of one's society should be viewed and also defines the role each will play within a given society. The cultural template additionally teaches one basic concepts of space and time. 
The significance of culture as a variable in the study of communication should not be underemphasized. A culture represents a way of life for a group of people; it provides a guide by which to live. Thus, the process of communication is itself guided by cultural patterns; the potential difficulties which can result from this fact are discussed later. ${ }^{4}$ More important, however, is the role communication plays in the transmission of cultural patterns themselves. Culture is learned through a communication process. The acquisition of a culture involves learning to recognize and categorize patterns of internal and external human relationships which, when conceived holistically, comprise an interrelated, coherent system that feels normative to the cultural member.

In effect then, culture is the instrument of human identity. As Hall (1977) contends:

- . in fact, what gives man his identity, no matter where he is born, is his culture, the total communication framework: words, actions, gestures, postures, tones of voice, facial expressions, the way he handles time, space and materials, the way he works, plays, makes love, and defends himself. All these things and more complete communication systems with meanings that can be read correctly only if one is familiar with that behavior in its historical, social, and cultural context (p. 42).

Identity labels the total experience of human beings within specific cultures and provides us with models for every conceivable human activity. For instance, when infants are born, only they do not know who they are. Their cultural cohabitants know exactly who the babies are, 
what language they will speak, what most of their behaviors will be, at what age they are most likely to marry, how many wives, husbands, or children they might have, and when they are most likely to die. ${ }^{5}$ In summary, contained within cultural patterns is all information regarding one's cultural identity: the relation of one's self to family, community, social and religious organizations, to nature and the universe.

Culture manifests itself through nonverbal behavior and in patterns of language (Samovar and Porter 1982, p. 3). The significant role which language plays in the formation of cultural identity is of particular concern here: in this study, changes in attitude toward language-viz. selected descriptive modifiers--are measured as an indication of changes in the tendency toward evaluation. 6 Support for the strong relationship between language and culture is found in the work of linguistic anthropologist Edward Sapir. According to Sapir (1949), language plays the role of a "guide to social reality."

- . (T)he real world is to a large extent unconsciously built up of the language habits of the group. No two languages are ever sufficiently the same to be considered as representing the same social reality. The worlds in which different societies live are distinct worlds, not merely the same world with different labels attached (p. 165).

One's reality is thereby structured by language, since language categorizes and labels one's experience. Therefore, according to Sapir, two different cultures may 
have, not only different languages, but consequently different world views.

As cultures differ, so does their communication. Communication differences go far beyond simple language barriers. One may not successfully communicate with someone from another culture even if both speak the same language. Cultural views frequently clash when evaluations based upon assumed similarities eventually prove erroneous, and what was thought to be a similarity in worldview is revealed instead to be a dissimilarity--a disagreement with one's assumptions, beliefs, values, or attitudes.? Unfortunately, simply eliminating the language barriers is insufficient to ensure successful intercultural communication, because the spoken word is only one element of the communication system. In fact, a shared language may, in some cases, lead to increased sense of threat and, consequently, more evaluation. After all, when there are language skills in common, it is easy to assume other similarities--even though, as mentioned above, such an assumption may be without foundation. Whether or not a language is shared, differences in the overall communication systems will often lead to increased evaluation.

Cultural patterns, then, not only encourage individual evaluative behavior, but also allow individuals to evaluate without questioning their right to do so. Such attitudes further provide the foundation for development of ethnocentrism as mentioned earlier. Failure to 
appreciate that one's values are not absolute nor universal, that criteria useful in one cultural context may be meaningless, or destructive, when applied in another, is common among people with little knowledge of cultural differences (Samovar and Porter 1982, p. 10). Each culture develops perceptual sets through which social phenomena are observed and implemented. These perceptual sets function as selective filtering processes and determine what stimuli to attend to as well as what meaning to attach (Samovar and Porter 1982, pp. 9, 10). People who use different sets may, from an ethnocentric perspective, be evaluated negatively as threats.

In this section, a definition of culture has been presented, and the relationship of cultural patterns to evaluation in communication has been considered. As has been shown, culture gives man his identity; the cultural identity is passed down through generations by the various cultures' communication systems, a process also known as socialization. Next, the problem which evaluation represents in intercultural communication is examined.

\section{EVALUATION AS AN INTERCULTURAL COMMUNICATION PROBLEM}

As noted earlier, communicating intraculturally may often be a threatening experience, since communication itself occurs within the context of change, and resistance to change is an accepted fact of life (Rogers 1961, p. 133). 
Communication exposes the person to the values, assumptions, and beliefs of others and creates a context in which one is forced to compare and measure one's own worldview against those of others. Nevertheless, the difficulties which evaluation of this sort can cause need not be serious; selective perception according to one's own criteria and appropriately assumed similarity with one's own countrymen will facilitate success in intracultural communication.

The situation becomes considerably more problematic when it involves communication with someone from a different culture. Because it is likely that there will be a divergence of perceptual and communicative systems employed by the communicants in an intercultural situation, and that there might be limited acknowledgment of these fundamental differences, serious problems can easily develop. A typical scenario in which these problems can develop involves the following elements.

1. Subconsciously influenced by their own cultural upbringing, people begin by believing that the needs, desires, and basic assumptions of others are nearly identical to their own (Hall 1967, p. 39). This assumption of similarity, because it is often groundless and out of awareness, is likely to be at the root of serious misunderstandings which may result.

2. Each time a message is exchanged and the response is contrary to what cultural criteria would lead one to 
expect, the misunderstanding triggers increased defensiveness and evaluation.

3. The reciprocal nature of communication suggests that this evaluative response will be mutual, leading to increasing defensiveness and frantic attempts to repair the misunderstandings.

4. The problem worsens because most communicators maintain their inappropriate basic assumption of similarity while retreating to familiar, culturally-based problem solving techniques.

Misunderstandings need not become devastating if, as in intracultural communication, communicants can recognize and acknowledge miscommunication to each other. However, in intercultural communication this direct intervention is seldom successfully attempted because basic cultural assumptions are not easily accessible to consciousness and perceptual differences can interfere with a direct comparison of impressions (Barna 1982, p. 324). Thus, as inappropriate problem solving techniques are applied, with no apparent success, reciprocal defensive and evaluative responses accelerate into an ever-worsening spiral of confusion and misunderstanding.

The above characterization, while exaggerated, shows how evaluation can create serious problems in intercultural communication. The detrimental effects of evaluation, however, can be avoided as they usually are in intracultural 
communication. Intercultural communicators can learn to avoid groundless assumptions which result from feelings of being evaluated for unknown reasons by another. It is with this goal in mind that intercultural communication trainings like the ICW have been created: to teach communicators to decrease culture-bound evaluation.

Recognizing how deeply ingrained the phenomenon of culture-bound evaluation appears to be, the task of the ICW would seem too difficult, perhaps even impossible to accomplish within the limited number of hours of an average college course. While elimination of culture-bound evaluation, whether positive, neutral, or negative, may be the ultimate goal of intercultural communication education and training, the ICW is only an introductory course taught largely to freshmen and sophomores. It therefore seems implausible to expect this workshop to result in a total elimination of culture-bound evaluation; it is more reasonable to expect this goal to be reached only after years of education, training, and interaction with individuals with varied cultural backgrounds.

Thus, the general objective of the ICW is not to eliminate culture-bound evaluation, but begin to decrease it. Specifically, the ICW appears to encourage this process by facilitating a movement from negative culturebound evaluation towards more positive evaluation. The ICW training thereby initiates a learning process which, 
it is hoped, may continue for the majority of the students until they eventually might reach the ideal state of knowing how to refrain from any nuance of negative or positive culture-bound evaluation.

The present study will therefore investigate if such a movement has indeed taken place: that is, if an increase in positive evaluation has occurred for the students enrolled in the ICW as a direct result of the training received in this workshop.

\section{SUMTIARY}

In Chapter I, relevant communication concepts which have direct application to evaluation were introduced and discussed. Such factors include the isomorphism of person perception and evaluation, the essential nature of evaluation as an inherent part of culture-bound evaluation on intercultural communication where it leads to communication problems. Finally, one of the primary goals of the ICW-decreasing culture-bound evaluation--was addressed. Chapter II will discuss how an educational strategy might address the problem of culture-bound evaluation. 
Chapter I--Notes

${ }^{1}$ For various ways of measuring interpersonal "judgment," attitudes, and attitude change, see the work of Roger Brown (1965), S. E. Asch (1946), and A. S. Iuchins (1957) in Tubbs and Moss (1977) basic speech communication textbook Human Communication. Communicology: An Introduction to the Study of Communication by Devito (1978), includes an exercise called "the Related Attitudes Game." Research in this area by Byrne and Clore (1966), Byrne and Nelson (1965), Byrne et al. (1970), and Osgood and Tannenbaum (1957) is referenced in Introduction to Interpersonal Relations by Clifford H. Swenson, Jr. (1973). Beliefs, Attitudes and Human Affairs by Bem (i970) and Theories of Human Communication by Littlejohn (1978) refer to a series of studies by M. Rokeach. In this context, it also seems relevant to mention the group of theories known as "consistency" or "balance" theories by Leon Festinger, Fritz Heider, and Theodore Newcomb. These theories are frequently referred to in numerous communication texts; and an example in point being that these theories are referenced in all of the five texts mentioned here.

\section{${ }^{2}$ Ruesch and Bateson (1968) say this about culture:}

"'Culture' as such cannot be observed directly; it only exists in the form of generalized statements made about social scientists about people, which include not only the specific organizational patterns of people in groups, but also their judicial and economic problems, their language and systems of symbolization, their conventions and traditions, and all objects, buildings, and monuments which convey some message from the past" (p. 40). Dorothy Iee (1959): "Culture is not, I think, 'a response to the total needs of a society'; but rather a system which stems from and expresses something had, the basic values of society" (p. 76). Hall (1967) defines culture in the following way: "Culture is the link between human beings and the means they have of interacting with others. The meaningful richness of human life is the result of millions of possible combinations involved in a complex culture" (p. 166). White and Dillingham (1973) have this to say: "Man and culture constitute an inseparable couplet. By definition there is no culture without man and there is no man without culture. All definitions are arbitrary. This does not mean, however, that they are not valid, that they are not justifiable, that they are not useful and truthful. But all definitions are arbitrary. They are man-made" (p. 9). And lastly, here is Samovar and Porter's definition (1982): "Culture is an intriguing concept. Formally defined, culture is the deposit of knowledge, experiences, beliefs, values, 
attitudes, meanings, hierarchies, religion, timing, roles, spatial relations, concepts of the universe, and material objects and possessions acquired by a large group of people in the course of generations through individual and striving" ( $p .31$ ). The definition actually goes on to also include language, behavior, styles of communication, geographical environment and technical development. ous terms.

${ }^{3}$ Please see Appendix A for definition of these vari-

${ }^{4}$ Please see the next section in this chapter on "Evaluativeness as an Intercultural Communication Problem."

5 From a lecture by Dr. Hugo Maynard, Department of Psychology, Portland State University.

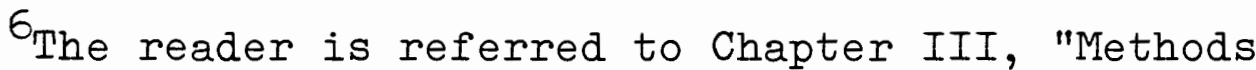
and Procedures" for discussion of methodology used to measure changes in the tendency toward evaluativeness through the use of descriptive modifiers (adjectives).

7 The reader may again find it of benefit to refer to Appendix A for definitions of these terms. 


\section{CHAPTER II}

\section{INTERCUITURAI COMMUNICATION EDUCATION :}

\section{NEEDS AND APPROACHES}

Chapter II will discuss the possible alleviation of negative culture-bound evaluation through education. Some suggested educational approaches will be examined with specific focus on the Intercultural Communication Workshop (ICW). The ICW's approach to alleviating negative culturebound evaluation through its group process format will be discussed in detail.

As discussed in the previous chapter, evaluation appears to be a socially learned characteristic and inherent in any cultures' patterns. The question is how to overcome this learning when the evaluation is negative and unsubstantiated as is frequently the case in intercultural encounters. One solution which has been suggested by many researchers is to alter previous learning through education. Evaluation has also been shown to create problems for those attempting to communicate interculturally because it can lead to misunderstanding. Through education we may learn to refrain from evaluating behavior stemming from different cultural patterns. An educational approach may make it possible to recognize situations where withholding judgment in an intercultural encounter will 
facilitate successful communication. As Hall (1977) proposed:

- . the only way man can escape the hidden constraints of covert culture is to involve himself actively and quite consciously in those parts of his life that he takes most for granted.

What is called for is a massive cultural literacy movement that is not imposed but springs from within... Man can benefit from more as well as a deeper knowledge of what an incredible organism he is. He can grow, swell with pride, and breathe better for having many remarkable talents. To do so, however, he must stop ranking either people or talents and accept the fact that there are many roads to the truth and that no culture has a corner on the path or is better equipped than no others to search for it (p. 7).

If intercultural education is to accomplish what Hall says is needed, then it must have clearly defined goals and objectives. Toward this end several directions have been proposed.

\section{WHAT SHOULD BE THE OBJECTIVES OF INTERCULTURAI COMIIUN ICAT ION EDUCATION?}

Hoopes and Rhinesmith (1972) suggest a method for preparing individuals for intercultural encounters by developing greater awareness for traditions, beliefs, values, and behavior of others as well as of ourselves. They contend that persons can function successfully abroad only when they are:

1. Aware of themselves as culturally conditioned individuals.

2. Alert to the differences in perception which exist between themselves and others.

3. Aware of their own social and emotional needs and attentive to those same needs in others. 
4. Are willing to work actively toward meaningful relationships with others, through the development of skilis, communication and interpersonal association (p. 22).

Those four points indicate some of the most impor-

tant ingredients in intercultural communication education aimed at increased ability to communicate successfully with a person from another culture. Hull (1972) agrees when stating the following goals for the Cross Cultural Interaction Workshop:

1. To enable the participants to gain an understanding of the particular values which are a part of himself when he approaches a different culture.

2. To enable the participant to begin to be sensitive to the cultural values which are part of others present in the group.

3. To enable the participant to understand and feel some of the uniquely individual differences that are part of a particular individual from a diverse culture and which are significantly his, and his alone, regardless of his cultural background ( $p .47)$.

These views suggest that the general aims of intercultural communication education should be to make students aware of their own values, the values of members belonging to other cultures, and individual differences which always exist among members within a given culture. Educational objectives such as these may increase understanding and empathy among various cultures.

However, most intercultural education commonly teaches students much about the content of culture; emphasizing descriptive information on "how people behave, why they 
behave as they do, and what the relationship is between human behavior and the environment" (Samovar and Porter 1982, p. 63). For example, students may learn how Americans accomplish objectives in ways which differ compared to the Japanese, the Middle Easterners, or Nigerians. One reason why many college courses emphasize culture content is that students may find it interesting to listen to a lecture describing operations of quality circle in Japanese corporations as well as the importance the Japanese place on age in performing correct greeting rituals. Students are further likely to appreciate an account of eating styles in Saudi Arabia and the unusual respect for elders exhibited by some Africans.

Theoretical orientations to culture identifies such "content" knowledge as cultural evolutionism, cultural functionalism, cultural history, and cultural ecology (Prosser 1978, p. 154). Leslie White refers to similar concepts using the terms "Culture Written Large" and "culture written small" where the first concept basically refers to the cumulative, collective experiences of humans and the second to how individuals interact within their own specific culture (Prosser 1978, p. 164). However, such information is not much use to intercultural communication education unless the emphasis is placed upon how these various ways of behaving influence the process of communication in an intercultural encounter. Objectives 
of intercultural communication education need to stress the development of a keen awareness of how the content-the "whats" of a culture--affect the "hows" of intercultural communication processes.

For example, a discussion of the interdependence of language and culture will provide the students with an increased understanding of any language's influence on perception and vice versa. Linguistic labeling is often arbitrary and ambiguous and frequently serves as an eye opener to developing the important awareness that the curious "how" is a better position from which to learn a new language than the "why" repeatedly asked in foreign language classes. The curious "how" position may also serve as a facilitator to intercultural communication through instilling an attitude of observing only how a member from another culture behaves and declining from having to interpret why in terms of one's own cultural norms. Invariably, the latter position leads to unsubstantiated negative evaluations.

To become familiar with nonverbal characteristics which differ from culture to culture is also important to students of intercultural communication. Nonverbal differences are often subtle and have a great impact on intercultural communication without the communicants' direct cognizance. Nonverbal aspects of cultural patterns further comprise a variety of behaviors which are understood and accepted only within the context of a specific 
culture's assumptions, beliefs, and values, since these constructs guide, rule, and regulate nonverbal communication. Therefore, subtle differences in nonverbal behavior, as well as overt ones, often cause unexpected and highly uncomfortable communication barriers. Since overt differences may be easier to isolate and identify, one may think that this softens the impact of the intercultural faux pas. Unfortunately, such is not the case. For example, it takes a great deal of intercultural education to reach the level of sophistication on the part of a Thai not to negatively evaluate a pat on the head. The close connection between one's values and culture-bound evaluation makes it crucial that any intercultural communication education includes a study of this concept. A value is defined as a "primitive preference for or a positive attitude toward certain end states of existence (like equality, salvation, fulfillment or freedom)" (Bem 1970, p. 17). Much intercultural miscommunication stems from clashes in value orientations. What may be sufficiently important from one cultural perspective to border on the sacred, may from another cultural viewpoint be considered far from that. One example of such differences in values is the American Indian's view of land as compared to the Caucasian American's. Furthermore, connotations of "good" and "bad" are attached to values and have a direct influence on whether intercultural communication will be successful. 
Through discussion of definitions of culture, the interdependence of language and culture, language's influence on perception, nonverbal behavior, and values, individual cultural patterns may become demystified through students' recognition of certain common characteristics among them. We all have families and friends, birth, adolescence, wedding and burial ceremonies, values, beliefs, and assumptions to mention only a few. Recognition of such categories provides the students with a foundation from which to descriptively compare cultural patterns in a nonevaluative way.

\section{WHAT IEARNING PROCEDURES SHOULD BE USED TO ACHIEVE THE EDUCATIONAL OBJECT IVE OF INTERCULTURAI COMIYUNICATION EDUCATION?}

While these objectives might be approached by educators through a variety of instructional methods, the goals themselves imply that experiential methods may be more efficient. The main goal of intercultural communication education is to teach students increased ability to successfully communicate with people from other cultures. Therefore, when developing curricula and class format for such an objective, educational planners need to consider particularly that communication is an activity in itself. The best forum for accomplishing such an objective, then, seems to be providing the students with direct experience 
of communicating with persons of different cultural backgrounds. The assumption is that exposure to other cultures' ways, and how these ways influence the communication process, is most effectively learned while actually experiencing communicating in intercultural encounters. Hall (1977) supports this assumption when stating:

An intercultural or interethnic encounter can be used to highlight otherwise-hidden structure points of one's own behavior at a rate many times faster than the normal exigencies of life will reveal that same hidden structure (p. 83).

Hall further seems to imply that learning accelerates in experiential situations. Support for experiential learning comes from various sources, e.g., Wallace 1977, p. 25; Laing 1971, p. 17; Dewey 1915, p. 3. One may say that experiential learning situations almost would force students to confront and overcome their own detrimental attitudes preventing them from successfully communicating with persons differing in cultural backgrounds. Homans (1961, p. 208) and Newcomb (1953, p. 395) also seem to support the theoretical notion that people learn communication skills by communicating when they state that increased attraction and agreement is directly related to propinquity.

In summary, intercultural communication eaucation necessitates concern for teaching generalized cultural principles and concepts enabling students to learn how cultures differ generally as well as how differences 
manifest themselves specifically for various cultures. Most importantly, such education must address the cultural differences' effect on the communication process. That students would benefit from learning these principles exposed to one another in interpersonal interaction is supported by communication theorists as has been discussed in the preceding pages. These criteria are basically followed in the format of the Intercultural Communication Workshop at Portland State University.

\section{GENERAL HISTORY OF INTERCULTURAI} COMIMUN ICATION EDUCATION

In 1966 experiments began in intercultural communication which resulted in the Intercultural Communication Workshop. The early explorations occurred at the University of Pittsburgh, Cornell University, and the University of Cincinnati. International student advisors took the ideas about culture and communication which had recently emerged and combined these with concepts and processes from humanistic psychology. The early Intercultural Communication Workshops lasted only about 2-1/2 days and consisted of lectures, films, exercises, group exercises, and simple discussion sessions. The attempt was made "to find out what would be most effective in helping participants in a multicultural group break through barriers to communication and interact on a deeper level than was normally the case" (Hoopes 1975, p. 3). 
INTERCULTURAL COMIUNICATION EDUCATION AT PORTLAND STATE UNIVERSITY

Since the Intercultural Communication Workshop at Portland State University is the focus for the present study, it may be interesting to look at the history of intercultural communication education and the Intercultural Communication Workshop at this institution.

The impetus for intercultural communication education began at Portland State in the mid-sixties when the Speech Communication Department was asked by the Department for English as a Second Language to teach pronounciation to the International students. IaRay Barna, Associate Professor of Speech Communication, soon became one of the first instructors to teach American pronounciation. Through Barna's exposure to International students as well as American students in the regular Speech Communication classes, she quickly became aware of the need for intercultural communication education. According to Barna, one particular incident stands out as clearly establishing this need: as an exercise in audience analysis she decided that the American students were to study the International students. Both groups of students were brought together in small group encounters enabling the American students to apply principles of analyzing an audience. It came as quite a surprise to Barna that, when subsequently the speeches were delivered, the International students 
did not understand much at all of what the Americans aimed to communicate to them. Thereby, it became obvious that more knowledge about each others' cultures was necessary to ensure an increase in the possibility for successful intercultural communication. Possessing adequate language skills was just not sufficient. Barna's International and American students were able to understand each other while communicating in the small groups, but the American students failed to take note of subtle cues from the International students, cues which would have enabled the Americans to deliver suitable speeches. Following this experience, Barna began bringing together International and American students in some of her classes. Difficult logistics soon made it apparent that a separate intercultural communication class was warranted. Thereby, the first class in intercultural communication education started at Portland State University, and before long it was included in the Speech Communication Department's regular curriculum.

This original intercultural communication class, offered at the lower division level, was replaced by the International Communication Workshop beginning Winter Term 1978. Dr. Milton Bennett has been its director since the workshop's inception. The ICW continues to be a success among the students with current enrollment of seventy to eighty students per term. 
THE INTERCULTURAI COMMUNICATION WORKSHOP: STUDENTS AND STRUCTURE

The Intercultural Communication Workshop provides intercultural communication education and skills training through the small group format. The intimacy and cohesiveness of this setting appear conducive to reaching the objectives of intercultural communication education by enabling its members to become better acquainted than would be possible in an ordinary classroom setting. The group thereby provides a context where International and American students can come together to study how different cultural, backgrounds affect the communication process. This context offers the students an experiential learning situation, and the intercultural communication principles learned within this context can easily be applied to intercultural encounters outside of the ICW. The ICW is available at the lower division level. Its students come from various disciplines. The large majority of the International students have previously taken coursework in the "English as a Second Language" program to improve their American language skills. Students enrolling in the ICW are required to have an adequate grasp of the English language, but any former knowledge of other cultures is not required.

The Workshop is offered as Speech 140 "Introduction to Intercultural Communication," which carries three 
quarter credits and meets once a week for three hours. The purpose of the course is to improve intercultural communication skills and cultural adaptation. Basic concepts of intercultural communication are discussed and differences between the American culture and other cultures are examined. Differences in traditions, customs, and values such as, for example, varied cultural patterns with regard to family and friends are explored. Through exercises students also learn specific communication techniques that are useful cross-culturally. (A complete course syllabus is shown in Appendix B.)

In order that adequate role models are available to share experiences and demonstrate the conceptual content of the workshop, facilitators for the ICW are carefully screened to ensure that each has both academic and experiential background in intercultural communication and skills in facilitating small groups. While facilitating these workshops the leaders receive weekly instructions as how best to teach important cultural concepts and communication skills to the students. Facilitation of the ICW is the major course requirement for a graduate seminar in which these students are enrolled. The class is offered as Speech 507 "Intercultural Facilitation," and its purpose is to provide training in group leadership in the particular skills of facilitating intercultural communication. (See Appendix C for further details.) 
Negative evaluation as an intercultural communication problem is addressed in various ways in the weekly meetings of the ICW. The tendency to negatively evaluate is identified as a major barrier to intercultural communication through discussions of cultural differences, ethnocentrism, stereotyping, and prejudice. Every meeting attempts to increase the students' knowledge of these concepts' affect on intercultural communication processes.

Perhaps the most important exercise in terms of focusing on evaluation is the DIE: Description, Interpretation, and Evaluation. This exercise clearly demonstrates it is possible to factually describe what we observe, make an interpretation of what is observed, and thirdly make an evaluation of that interpretation. Usually, these evaluations are stated in terms of whether the student likes or dislikes what is observed and interpreted. Before long it becomes apparent that the evaluations assume the nature of being either good or bad, and that the evaluations are tied to particular, sometimes arbitrary interpretations. This makes the students realize how subjective and culturally bound our interpretations and evaluations are. The DIE exercise is outstanding in showing how the same descriptions may result in several different interpretations and how the cultural context determines the outcome of an evaluation as either good or bad.

The BAFA BAFA exercise is a cultural simulation game which gives the students the opportunity to experience 
values and behaviors of another culture. It also teaches the students how it feels participating in a culture where one knows neither customs nor the language. The game provides experiential knowledge of evaluating another culture's behavior as well as obtaining a first hand sense of feeling personally evaluated by a person different in cultural background. To be evaluated negatively for unknown reasons--only with the understanding that a cultural norm has been violated--is indeed an experience which quickly teaches some important cultural lessons about the relativity of culture-bound evaluation.

The ICW teaches students that cultural differences manifest in various ways of behaving, feeling, and thinking. Throughout the workshop the facilitators emphasize that cultural patterns differ. Attention is continuously drawn to it not being necessary to evaluate different behavior and communication styles as being either good or bad. We can simply accept each others' ways as only being different without there being one particular right way for everyone nor a wrong way. The ICW thereby attempts to teach students that whatever seems appropriate for an individual culture is correct for that culture within the culture's own context. Other cultures may prefer different ways, and it is more conducive to successful intercultural communication to refrain from evaluating each others' behavior and rather develop the ability to appreciate the 
interesting differences which certainly exist within the various cultural patterns.

An initial step toward elimination of culture-bound evaluation altogether is to decrease the negative evaluations associated with ethnocentrism. The ICW, while holding out nonevaluation as an ultimate goal, does include considerable attention to the simple decrease of negative evaluation. It is this interim step that the present study addresses.

In summary, the ICW addresses evaluation as one of the most detrimental deterrents to communicating successfully across cultures, and makes the students aware of approaches which lead to rewarding intercultural encounters. These approaches are shown through exercises already mentioned, discussions of value clarifications, and nonverbal behavior, reading and writing assignments.

The ICW facilitators serve as role models by establishing the workshop's behavioral norms and by taking particular care to be accepting and nonjudgmental. A supportive group environment in which the student's develop trust in one another is created to the best ability of the facilitators. In this atmosphere, students become less afraid of exposing true feelings and opinions. Evaluation can thereby be confronted in a climate which is as nonthreatening as possible. 
In this chapter the possible alleviation of culturebound evaluation through intercultural communication was discussed. The first section has discussed why intercultural communication is needed, identified goals suggested by leading theorists in intercultural communication, and examined how these goals have been addressed nationally as well as at Portland State University through intercultural instruction. The format for the PSU workshop was described in detail, including how it approaches alleviating culture-bound evaluation in general, and how it begins that process by encouraging a move from more negative to more positive evaluation in intercultural situations. Chapter III will discuss the methodology and procedures used to investigate the ICW's success in reaching this goal. 
CHAPTER III

\section{METHODS AND PROCEDURES}

In Chapter III the research hypothesis and four subhypotheses are presented. The second section discusses development of the measuring instrument for assessing the ICW's affect on decreasing negative culture-bound evaluation. In the last section, subject selection and testing procedures, the coding of test responses, and the research design will be considered.

\section{HYPOTHESES}

Based upon the assumption that the ICW alleviates or decreases culture-bound evaluation, the following research hypothesis was established:

Hypothesis: After completing the ICW, student subjects will demonstrate a decrease in culturebound evaluation by exhibiting an increase in positive evaluations of an International/ American (I/A) student dyadic interaction as compared to their student peers with no ICW training.

This main hypothesis generated four sub-hypotheses applicable to the specific populations tested: 
Sub-hypothesis 1: After completing the ICW, American student subjects will demonstrate a decrease in culture-bound evaluation by exhibiting an increase in positive evaluations of an I/A student dyadic interaction as compared to their student peers with no ICW training.

Sub-hypothesis 2: After completing the ICW, International student subjects will demonstrate a decrease in culture-bound evaluation by exhibiting an increase in positive evaluations of an I/A student dyadic interaction as compared to their student peers with no ICW training.

Sub-hypothesis 3: After completing the ICW, American student subjects will demonstrate a decrease in culture-bound evaluation by exhibiting an increase in positive evaluations of an I/A dyadic interaction as compared to before the ICW training. Sub-hypothesis 4: After completing the ICW, International student subjects will demónstrate a decrease in culture-bound evaluation by exhibiting an increase in positive evaluations of an I/A dyadic interaction as compared to before the ICW training. 


\section{DESIGNING THE "FIRST IMPRESSION TEST"}

To test these hypotheses a two-page test named the "First Impression Test" was devised. The test asked the subjects to evaluate what an American student is thinking about an International student and what this International student is thinking about the American student.

To express their evaluations of the intercultural dyads, the subjects were provided with a collection of thirty adjectives which made up the test's second page. The test's first page consisted of ten incomplete sentences. In order to complete each sentence, each subject had to select six adjectives from the thirty available. These adjectives had already been scaled into positive, neutral, and negative categories without the knowledge of the subjects, and the scaling process will be explained later in this chapter. The dyadic pictures were always presented as slides. (See Appendix D for the complete test.)

The indirect method of measuring attitudes has been influenced by both the concept of "metaperspective" (Laing, Phillipson, and Lee 1972, p. 5) and "attribution theory" (Heider 1958, p. 296). Metaperspective is defined by Watzlawick:

When we no longer use communication to communicate but to communicate about communication, as we inevitably must in communication research, then we use conceptualizations that are not part of but about communication (Watzlawick, Beavin, and Jackson 1967, p. 40). 
The assumption of attribution theory is that "attribution refers to judgments made about the behavior of others as well as to judgments about one's own behavior. The basic assumption is that people actively seek out explanations for the behavior they observe" (Brislin 1981, p. 91).

These combined concepts coupled with the necessity for a manageable and consistent test situation resulted in the decision to expose subjects to an intercultural interaction without having to report their own direct responses. Furthermore, giving the subjects the opportunity to report their metaperspectives may have allowed for a more honest response by relieving them of the responsibility of directly evaluating an intercultural dyad (Sherif and Hovland 1953, p. 135).

\section{Summary of the Design of}

\section{the Test Instrument}

The "First Impression Test" was developed by a procedure consisting of three distinct processes: (1) selection of adjectives, (2) obtaining photographs of intercultural dyads, and (3) wording of the test itself. An initial sixty adjectives subjectively selected by the investigator were rated by International and American student subjects on a seven to one rating scale--seven indicating high positive and one, low negative value. These adjectives were scored according to a computation 
process which is explained in detail later in this chapter, a reliability study was administered, and thirty adjectives with negative, neutral, and positive values were finally selected and listed on the second page of the "First Impression Test."

Photographs were taken of five male dyads; three intercultural and two same culture dyads. These photographs were developed into slides which were projected onto a screen in the actual test situation.

The wording of the test was written as simply as possible to accomodate the International student subjects with marginal language skills. (See Appendix D for a copy of the test.)

\section{Developing the Adiective Scale}

Twenty positive, twenty neutral, and twenty negative adjectives were subjectively selected by the investigator according to the following criteria:

1. Adjectives considered to be commonly used by the target population to be tested.

2. Adjectives describing personal characteristics.

3. Adjectives other than those describing personal characteristics in terms of physical attributes (e.g., thin, fat, tall, and short).

From the initial list of sixty adjectives, twenty-one were deleted and thirteen others added according to the investigator's estimation of the International students' level of understanding. This resulted in the following fifty-two adjectives: 
Rude, jealous, corrupt, assertive, colorful, imaginative, friendly, serious, cautious, unfriendly, quick, brave, curious, talkative, shy, patient, dirty, clever, lazy, dependable, kind, violent, firm, loyal, believable, loud, dangerous, trustworthy, creative, realistic, generous, interesting, rich, careless, shrewd, surprised, slow, spontaneous, thorough, critical, practical, idealistic, false, truthful, indifferent, studious, weak, thrifty, cheerful, modest, impolite, intimate. These adjectives' positive, neutral, and negative connotations were determined by collecting responses from samples of American and International students. Men and women enrolled in "Basic Speech 100" and "English as a Second Language" (ESL), Advanced Level 3, assigned numerical values to the adjectives, which corresponded to the subjects' perception of the words as more or less negative. A check of comprehension was administered to the International subjects, but not to the American subjects, since the adjectives were considered common language usage of American students. (The resulting two tests are shown in Appendix E.)

Prior to determining the adjectives' value, the American students received the following instruction orally and also in writing at the top of the test sheet:

If you used this word to describe another person, would you be complimenting or criticizing him or her? 
The International students were given these instructions in writing and orally:

If you used this word to describe another person, would you mean to be complimenting (saying something positive about) or criticizing (saying something negative about) him or her?

Thirty-six American students and thirty-seven International students participated in the initial study.

Scoring the Adjectives

Paralleling Dawes' (1972) Direct Estimation Techniques, an average score per adjective, as assigned by the initial raters enrolled Winter Term 1980, was needed to determine the adjectives' positive, neutral, or negative connotations. The investigator determined to compute the average score per adjective in the following way:

1. The values of 7 to 1 were listed vertically below each adjective tested--three adjectives only per each sheet of paper.

2. Each student's assigned value per adjective (a possible $1,2,3,4,5,6$, or 7) was marked by a ( 7 ) next to the vertically listed number indicating the assigned value. This process was repeated for every adjective from every student in the two groups, keeping the International and the American values separate.

3. Next, each $(\checkmark)$ was counted and recorded to the immediate right of the value indicated. This figure represented the number of students who had assigned a rating to a given adjective.

4. Each value was then multiplied by the number of students who had assigned the same value to a particular adjective. Six students assigned the value of 3 to "rude" resulting in the product of 18. Each product was recorded at the very right hand side of the sheet of paper. 
5. The figures obtained through step four were added and divided by the number of students participating. Thus an average student score for each adjective was arrived at. Since all the students did not respond to each adjective, the divisor fluctuated slightly from adjective to adjective.

A visual representation of the above process is easier to follow and is shown in Appendix F.

Since differences in values, beliefs, and attitudes between International and American students would result in different responses on the seven to one continuum for the same adjectives, it was necessary to establish two separate scales with separate values for International and American positive, neutral, and negative categories.

The seven-point rating scale was also used for the International students' understanding of the adjectives.

\section{Selecting the Adjectives}

The adjectives used in the final test--the "First Impression Test"--were selected according to the following criteria:

1. Level of understanding by the International students was 5 or above.

2. A value from 0 to 2.99 indicated a negative connotation.

3. A value from 3 to 4.99 indicated a neutral connotation.

4. A value from 5 to 7.00 indicated a positive connotation.

5. Adjectives determined to be in mixed categories, e.g., defined by the International students as having a neutral value and the American students as having a 
positive value for the same adjective, were excluded. It was considered important to the study to select adjectives which minimized discrepancy between two student groups in the perceptions of positivity, neutrality, or negativity.

6. Positive adjectives were those with a score of 5 or above with the difference between International and American values not to exceed 1.00. Neutrals were the ones that ranged from 3.00 to 4.99. Negative were those below 2.99 and where difference between International and American values did not exceed 1.00 .

7. For the selection of adjectives to be manageable in the test.situation, it was decided that only thirty adjectives were to be listed on the "First Impression Test."

Criterion number one, "level of understanding by the International students," deleted these adjectives:

Corrupt, assertive, thrifty, modest, intimate, shrewd, spontaneous, and thorough.

This meant that the International students' average score for the adjectives was 4.99 or less, since for an adjective to be included it had to have a score of 5 or above. Criterion number six, "differences between International and American values not to be greater than 1," deleted:

Imaginative, patient, violent, and cheerful. These adjectives, then, had a score difference greater than 1 between the International score and the American score as, for example, in the adjective "violent." This adjective showed a difference of 4.64 since the International students had an average score of 5.97 and the American score was 1.33. Twenty-six International students gave "violent" the highest positive score of 7 and twenty-six American 
students gave this adjective the highest negative score of 1. There were a total of thirty-seven International students and thirty-six American students participating in this study. Conversely, and interesting to note in this context, the adjective "kind" was given the highest positive score of 7 by thirty-five International and thirtyone American students.

Criterion number seven, which was "adjectives not to exceed thirty in number in order to make the selection of adjectives manageable in the test situation," deleted:

Generous, truthful, and indifferent.

These adjectives were randomly selected. (The remaining thirty adjectives are shown in Appendix G.)

\section{Reliability Study}

A correlational study was conducted to determine the reliability of the adjective rating. The students who participated in the correlational study were enrolled in "Basic Speech 100" and "English as a Second Language" (ESL), Advanced Level 3, as were the students who participated in the initial rating of the adjectives. However, the initial raters were enrolled Winter Term 1980, and the students who participated in the correlational study (eighteen American and twenty-five International students) were enrolled Summer Term 1980. The Summer Term students received similar procedures to the initial raters. However, there were three exceptions: (1) the raters' names were 
asked for, (2) only the thirty adjectives listed in the "First Impression Test" required a response, and (3) since the initial raters had already determined the level of understanding by the International students for these adjectives, a check on comprehension was not administered (again, see Appendix F). There was approximately two weeks between the first and the last rating.

A Pearson correlation coefficient test-retest study correlated the scores from these two ratings. The reliability level was set at $r=.40$. This relatively low coefficient was considered to represent an adequately reliable level for inclusion of a single item in the main test, the "First Impression Test." (See Appendix H for correlations.)

The adjectives "shy," "studious," "believable," and "realistic" were found to be unreliable for the American students and "shy," "quick," "slow," "lazy," "critical," and "interesting" lacked reliability for the International students.

The following adjectives were found reliable. They are listed with their Pearson $r$ reliability coefficients: 
International $(n=25)$

Jealous

Clever

False

Unfriendly

Impolite

Kind

Rude

Creative

Careless

Dangerous

Surprised

Talkative

Dirty

Firm

Brave

Practical

Studious

Colorful

Believable

Realistic

Weak

Cautious

Dependable

Friendly
.82

.81

.70

.40

.60

.53

.52

.56

.58

.53

.47

.51

.44

.55

.65

.55

.67

.55

.70

.61

.54

.40

.48

.52
American $(n=18)$

Jealous

.76

Clever

.65

False

Unfriendly

.44

Impolite

.76

Quick

.46

.60

Kind

.78

Rude

.59

Creative

.61

Careless

.67

Dangerous

.58

Surprised

.65

Talkative

.51

Friendly

.71

Dirty

.40

Firm

.45

Slow

.47

Brave

.71

Practical

.65

Lazy

.93

Colorful

.58

Critical

.59

Weak

.55

Interesting

Cautious

.47

.58

Dependable

For a global assessment of reliability of item weighting, total scale scores were computed for all subjects' test and retest data. For the eighteen American subjects, a Pearson $r$ of .71 was obtained with test and retest means of 126.44 and 123.72 respectively. For the 
International subjects, a Pearson $r$ of .72 was obtained with test and retest means of 121.44 and 120.32 , respectively.

The reliability study was computed on a Litton microcomputer "Compucorp" model "Monroe 344 Statistician."

\section{Developing Slides of International/}

American Dyads

Projected slides of International/American student dyads were decided to appropriately serve as evaluation targets as slides would assure uniformity to each test situation. Use of live humans in these situations would have introduced an uncontrollable variable into the testing procedures, since it most likely would have been impossible to make sure that facial expressions remained the same during the eight occasions the "First Impression Test" was administered.

Five male dyads were photographed: American/American, American/Saudi Arabian, American/Japanese, American/ American, and American/Black Libyan. The two same-culture dyads were included as blinds in order to avoid communicating to the test subjects that data collection was purely for an intercultural purpose. Hopefully, the subjects would thereby be less self-conscious of being tested for their intercultural attitudes allowing for more honest responses.

One American student was photographed with a student from Saudi Arabia, Japan, and from Libya. This American 
student was also photographed with a second and a third American student. Thereby three American students were involved. All of the six students attended Portland Community College at the Sylvania Campus. Since the subjects to be finally tested would be from Portland State University, another campus was chosen for the photographs to avoid a possible familiarity with the students photographed by the students tested. Only male students were selected for two reasons: there are more International male students studying in Portland than there are female, thereby making males more typical of the International student population at Portland State University; using only one sex eliminated the sex variable in the testing situation.

Thirty photographs were taken and developed into slides. The five slides to be used as part of the "First Impression Test" were selected by the investigator. This selection process consisted of judging what five photographs had the most noncommittal facial expressions as determined by showing as little indication as possible of any positivity or negativity. Therefore, the selected slides show no laughter or smiles, anger or frowns. (See Appendix I.) The procedure minimized influence on subjects by any display of emotions from the projected dyads when choosing adjectives with which to complete the sentences in the "First Impression Test." 
The "First Impression Test":

Concluding Details

Prepared with the list of adjectives and slides, details of the final test were worked out. The test was named the "rirst Impression Test" and consisted of a paper and pencil test where subjects were asked to perform sentence completions of their impressions of what the American student (a) thinks about the International student, and (b) vice versa. The adjectives with which to complete the sentences were selected from the list of scaled adjectives only. As mentioned earlier, these adjectives were listed separately on the second page of the "First Impression Test." To avoid the possibility of repetitive use of certain adjectives listed at the top and the bottom of the lists, the adjectives were assembled into five distinct lists through a process which simply reversed the order of the preceding list. When administering the "First Impression Test" in the actual test situation, an equal number of these lists were distributed among the subjects (see Appendix J).

\section{SUBJECT SELECTION AND TESTING PROCEDURES}

\section{Summary}

The "First Impression Test" was administered to American and International subjects enrolled in the ICW and to American and International subjects enrolled in 
"Basic Speech Communication 100" and "English as a Second Language," Advanced Level 4; these last groups serving as control subjects. The testing procedures lasted for about 20 minutes and consisted of the subjects responding to the photographs of the five dyads projected as slides onto a screen by recording the responses on the "First Impression Test." The subjects were asked to select their responses from the thirty adjectives listed on the second page of this test.

The recorded test responses were subsequently coded with their appropriate values, International responses with International values and American responses with American values. Since each projected slide required six responses, one total sum per slide was arrived at by adding the six coded adjectival values, and thereby five distinct sums were obtained for each subject tested. The following section of this chapter will detail the subject selection and testing procedures.

\section{Subject Selection}

A total of 181 subjects were tested: 109 Americans and 72 International subjects. The study groups were enrolled in the ICW Winter and Spring Terms of 1980. Both groups were tested on the last day of class. The Spring Term subjects were also tested on the first day to determine whether an interest in intercultural communication education was already manifesting itself in a more positive 
attitude toward people from other cultures. The control subjects were enrolled Spring Term 1980 in "Basic Speech Communication 100" and "English as a Second Language," Advanced Level 4.

These subjects were selected on the basis of their equivalence to the ICW subjects. Enrollment in the ICW draws heavily from both "Basic Speech Communication 100" and "English as a Second Ianguage." One may therefore assume that many of the ICW subjects investigated in this study have either one of these classes in their background. Some subjects may have both. It is unusual in either class to have already taken the ICW.

\section{Testing Procedures}

Upon distributing the test the students were asked to carefully read the following instructions for the "First Impression Test":

You will be shown a picture of two people in a conversation. We will refer to the people as $A$ and B. Don't worry about what they are saying. Instead, imagine what each one is thinking the other one is like.

Please turn to the attached sheet and choose three words that best describe what each one is thinking the other one is like and complete the sentences below.

Do not use words which are not on the list.

These instructions were also read out loud by the experimenter. The following directions were given orally only:

You may use each word more than once, but not for the same person.

Before the test begins, you will have two minutes to study the word list. This list may be separated from the test sheet if you wish. 
When the test begins, each slide will be shown for three minutes. When two minutes have passed, one minute left will be announced.

Subjects were allowed to ask questions to clarify the test.

The slides of the five dyads were subsequently projected onto a screen. The American shown in each slide was identified as "A" and his dyadic partner as "B" by posting large letters cut from cardboard beneath the appropriate character projected on the screen. The slides were projected in the following order:

1. Two Americans

2. American/Saudi Arabian

3. American/Japanese

4. Two Americans

5. American/Black Iibyan

Each test period lasted approximately thirty minutes.

\section{Coding Test Responses}

The adjectives selected by the subjects with which to complete the ten sentences in the "First Impression Test" were coded with their scaled negative, neutral, and positive values respectively; the International subjects' adjectives with International values, and the American subjects' adjectives with American values.

In order to carry out this coding, it was crucial to have each blank in the "First Impression Test" completed. However, subjects missed completing certain blanks resulting in $.80 \%$ missing out of a possible 4,470 . 
There were 149 subjects participating in the "First Impression Test" and each subject had to fill in 30 blanks; $149 \times 30=4,470$. Additionally, the test was administered with certain adjectives which later proved unreliable. As mentioned earlier in this chapter, the reliability study showed that four adjectives were unreliable for the American students and six for the International students.

Responses using these unreliable adjectives made up $15.01 \%$ of all responses.

The decision was made by the investigator to compute averages for missing and unreliable adjectives in order to have each blank filled in the "First Impression Test." This was accomplished in the following way:

Missing adjectives. If an adjective(s) were missing, the adjectives completed were added and divided by the number of the ones present. The quotient was used as the missing adjective(s) value.

Unreliable adjectives. The reliability study was used to compute functional averages for the unreliable adjectives. Each unreliable adjective's highest and lowest rating in the 7-point graphic rating scale were added, the sum was divided by 2 , and the quotient was used as the value for the unreliable adjective.

A value for each adjective used in the "First Impression Test" was thereby obtained.

One sum per dyad-slide per subject was thus arrived at by adding the coded adjectives--six values for each 
completed sentence. This resulted in obtaining five distinct sums per each test per subject. These five sums per subject served as the computer data file.

The highest possible sum of values an American could choose as a response to a projected slide--six blanks filled-was 38.05 by selecting friendly (6.78), kind (6.83), creative (6.61), interesting(6.19), colorful (5.78), and brave $(5.86)$. The most neutral sum was 23.58 by selecting cautious (4.42), talkative (4.17), shy (3.58), surprised (4.39), critical (3.19), and dependable (3.83). The lowest possible negative sum was 10.89 by selecting rude (1.53), impolite (1.89), dirty (1.86), dangerous (1.78), false (1.94), and lazy (1.89).

The highest possible sum of values an International subject could choose as a response to a slide--again six blanks filled--was 37.94 by selecting brave (6.09), colorful (6.17), interesting (6.46), friendly (6.51), clever $(6.28)$, and kind (6.43). The most neutral sum was 23.82 by selecting cautious (4.62), talkative (3.79), shy (3.12), firm (4.73), critical (3.64), and dependable (3.92). The lowest possible negative sum was 10.30 by selecting rude (1.94), impolite (1.84), unfriendly (1.51), dirty (1.59), dangerous (1.66), and lazy (1.76).

This chapter has considered the research hypothesis, which generated four sub-hypotheses, and the development of the "First Impression Test." The objective of this 
test was to measure the ICW's affect on decreasing culturebound evaluations. The chapter also described the collection of data through administering the test and computing the sum of selected adjectives per projected slide of a dyad for each subject tested. The final section of this chapter will discuss the research design.

\section{THE RESEARCH DESIGN}

A modified institutional cycle design (Campbell and Stanley 1972) was used due to investigator inability to control the "to whom" of the experimental program. This quasi-experimental design permitted checks on selection bias and potential testing effects in addition to providing two differentially flawed comparisons for hypothesis testing. See Figure 1.

$$
\begin{aligned}
& \text { AMERICAN Ss } \mathrm{A} \mathrm{O}_{1}(n=19) \times \mathrm{O}_{2}(n=17) \\
& \text { B } \\
& \mathrm{x}_{3}(\mathrm{n}=20) \\
& \text { C } \\
& \mathrm{O}_{4}(\mathrm{n}=50)
\end{aligned}
$$

INTER-

NATIONAL SS

$$
\begin{array}{ll}
\mathrm{D} \mathrm{O}_{5}(\mathrm{n}=18) & \times \mathrm{O}_{6}(\mathrm{n}=14) \\
\mathrm{E} & \times \mathrm{O}_{7}(\mathrm{n}=18) \\
\mathrm{F} & \mathrm{O}_{8}(\mathrm{n}=19)
\end{array}
$$

Eigure 1. Modified institutional cycle design

The "First Impression Test" was actually administered on eight separate occasions $\left(\mathrm{O}_{1}\right.$ through $\left.\mathrm{O}_{8}\right)$, twice to 
Groups $A$ and $D$ who were tested both before the ICW and after receiving the training. Group A subjects were American students who were pretested, took the ICW, and then posttested. Group B subjects were American subjects who took the ICW and were posttested only. Group C subjects were American subjects who did not take the ICW and were tested. Group D, E, and F subjects were International students who received identical procedures to subjects $A$, $B$, and $C$, respectively.

The next chapter will detail the statistical computations performed according to the "T-Test" and "ANOVA" subprograms in Statistical Packages for the Social Sciences (Nie et al. 1975) and run on a Honeywell 6640 computing system. 
CHAPTER IV

\section{RESULTS}

\section{DESIGN AND DATA COLIECTION SUMMARY}

Six subject groups were created by the procedures of the present investigation. Group A subjects were American subjects who were pretested, took the ICW program, and then posttested. Group B subjects were American subjects who took the ICW and were tested. Group C subjects were American subjects who did not take the ICW and were tested. Group D, E, and F subjects were International students who received identical procedures to subjects in Groups A, B, and $C$ respectively.

All measurement events $\left(\mathrm{O}_{1}\right.$ through $\left.\mathrm{O}_{8}\right)$ represent administration of the "First Impression Test" which measured decreases in culture-bound evaluation. Test development was described in Chapter III. Procedures produced total scores for the subjects' interpretations of three photographs (numbers 2, 3, and 5) of intercultural dyads and two photographs (numbers 1 and 4 ) of same-culture dyads. Only data generated by the intercultural dyad photographs were pertinent to the goals of this study. Photo numbers 1 and 4 were blinds. 
Results are presented in the order in which various data analyses were performed. Because of investigator inability to control the "to whom" of the experimental program, a modified institutional cycle design (Campbell and Stanley 1972) was used. This quasi-experimental design permitted checks on selection bias and potential testing effects, in addition to providing two differentiallyflawed comparisons for hypothesis testing. (See Figure 1, p. 59.)

The data analyses proceeded through the following four phases:

1. A check on selection bias by $O_{1} / O_{4}$ and $O_{5} / O_{8}$ comparisons.

2. A check on repeated testing effects by $\mathrm{O}_{2} / \mathrm{O}_{3}$ and $\mathrm{O}_{6} \mathrm{O}_{7}$ comparisons.

3. Hypothesis testing through comparisons $\mathrm{O}_{2}+\mathrm{O}_{3} / \mathrm{O}_{4}$ and $\mathrm{O}_{6}+\mathrm{O}_{7} / \mathrm{O}_{8}$ in a nonequivalent posttest only design.

4. Hypothesis testing through $\mathrm{O}_{1} / \mathrm{O}_{2}$ and $\mathrm{O}_{5} / \mathrm{O}_{6}$ comparisons in a one group pretest-posttest design.

\section{SELECTION BIAS}

As noted above, the first analysis checked a potential sampling bias on the part of the students who opted to take the ICW by comparing Group $A$ and D's pretest scores with Group C and F scores respectively. 
To check the sampling selection bias, (1) non-ICW subjects $\left(\mathrm{O}_{4}\right)$ were compared with ICW American subjects before training $\left(\mathrm{O}_{1}\right)$, and (2) non-ICW International control subjects $\left(\mathrm{O}_{8}\right)$ were compared with ICW International subjects prior to training $\left(\mathrm{O}_{5}\right)$. The results from all six fixed ANOVAS for these groups (three photos each for American and International Ss) established that there were minimal differences in evaluation between students who chose to enroll in the ICW and their non-ICW student peers. See Tables I and II.

\section{TABLE I}

ANAIYSIS OF VARIANCE FOR PRETREATMENT ICW $(n=13)$ AND CONTROL AMERICANS $(n=50)$ ON THREE PICTURES

\begin{tabular}{lrrrrr}
\hline \hline Source & SS & DF & MS & F & Sig. \\
\hline Groups & 20.911 & 1 & 20.911 & 0.536 & 0.467 \\
Residual & 2380.243 & 61 & 39.020 & & \\
Total & 2401.154 & 62 & 38.728 & & \\
\hline & & (Picture \#2) & & \\
Groups & 4.382 & 1 & 4.382 & 0.143 & 0.707 \\
Residual & 1869.537 & 61 & 30.648 & & \\
Total & 1873.919 & 62 & 30.225 & & 0.353 \\
\hline & & (Picture $\# 3$ ) & \\
Groups & 137.269 & 1 & 137.269 & 0.875 & \\
Residual & 9568.885 & 61 & 156.867 & & \\
Total & 9706.154 & 62 & 156.551 & & \\
\hline
\end{tabular}


TABLE II

ANALYSIS OF VARIANCE FOR PRETREATMENT ICW $(n=8)$ AND CONTROI INTERNAT IONALS $(n=19)$ ON THREE PICTURES

\begin{tabular}{lrrrrr}
\hline \hline Source & SS & DF & MS & F & Sig. \\
\hline Groups & 14.082 & 1 & 14.082 & 0.533 & 0.472 \\
Residual & 660.992 & 25 & 26.440 & & \\
Total & 675.074 & 26 & 25.964 & & \\
\hline \multicolumn{7}{c}{ (Picture \#2) } \\
Groups & 1.125 & 1 & 1.125 & 0.040 & 0.842 \\
Residual & 694.603 & 25 & 27.784 & & \\
Total & 695.728 & 26 & 26.759 & & \\
\hline & & (Picture & $\# 5)$ & & \\
Groups & 5.580 & 1 & 5.580 & 0.111 & 0.742 \\
Residual & 1261.428 & 25 & 50.457 & & \\
Total & 1267.008 & 26 & 48.731 & & \\
\hline
\end{tabular}

In addition, when comparing the means of non-ICW and ICW responses for both International and American Ss on each of three I/A pictures, there is an evenly mixed pattern of mean scores between non-ICW and ICW groups. See Table III. Based on these results, existence of a systematic selection bias favoring the hypothesis is not plausible. 
TABIE III

MEANS FOR ALI SUBJECTS

\begin{tabular}{ccc}
\hline & ICW & Non-ICW Controls \\
Picture & Before Training & No Training \\
\hline & $($ American Subjects $)$ & $(\mathrm{n}=50)$ \\
2 & $(\mathrm{n}=13)$ & 22.02 \\
3 & 20.60 & 20.92 \\
5 & 21.57 & 28.53 \\
& 32.18 & \\
& $($ International Subjects $)$ & $(\mathrm{n}=19)$ \\
3 & $(\mathrm{n}=8)$ & 23.60 \\
5 & 22.02 & 23.19 \\
& 22.74 & 26.23 \\
\hline
\end{tabular}

\section{TEST TNG EFFECTS}

The second analysis examined the potential repeated testing effect on the students who were pretested by comparing posttest scores of ICW subjects who were pretested $\left(\mathrm{O}_{2}\right.$ and $\left.\mathrm{O}_{6}\right)$ with those that were not pretested $\left(\mathrm{O}_{3}\right.$ and $\left.\mathrm{O}_{7}\right)$. It was necessary to check to what extent the pretested group's scores were inflated due to effects of the pretest beyond any treatment effects. These comparisons involved a total of 33 Americans and 26 International subjects. Again, no statistical differences were found in any of the six analyses of variance. See Tables IV, V, and VI. 
TABLE IV

ANALYSIS OF VARIANCE FOR PRETESTED $(n=13)$ AND NONPRETESTED $(n=20)$ ICW AMERICAN SUBJECTS

\begin{tabular}{|c|c|c|c|c|c|}
\hline Source & SS & $\mathrm{DF}$ & MS & $F$ & Sig. \\
\hline \multicolumn{6}{|c|}{ (Picture \#2) } \\
\hline Groups & 6.614 & 1 & 6.614 & 0.101 & 0.752 \\
\hline Residual & 2022.952 & 31 & 65.257 & & \\
\hline Total & 2029.566 & 32 & 63.424 & & \\
\hline \multicolumn{6}{|c|}{ (Picture \#3) } \\
\hline Groups & 1.287 & 1 & 1.287 & 0.038 & 0.847 \\
\hline Residual & 1050.982 & 31 & 33.903 & & \\
\hline Total & 1052.269 & 32 & 32.883 & & \\
\hline \multicolumn{6}{|c|}{ (Picture \#5) } \\
\hline Groups & 70.187 & 1 & 70.187 & 0.287 & 0.596 \\
\hline Residual & 7573.872 & 31 & 244.318 & & \\
\hline Total & 7644.059 & 32 & 238.877 & & \\
\hline
\end{tabular}




\section{TABLE V}

ANALYSIS OF VARIANCE FOR PRETESTED $(n=8)$ AND NONPRETESTED $(n=18)$ INTERNATIONAI SUBJECTS

\begin{tabular}{lrrrrr}
\hline \hline Source & SS & DF & MS & F & Sig. \\
\hline Groups & 12.927 & 1 & 12.927 & 0.304 & 0.587 \\
Residual & 1020.979 & 24 & 42.541 & & \\
Total & 1033.906 & 25 & 41.356 & & \\
\hline \multicolumn{7}{c}{ (Picture $\# 3$ ) } & & \\
Groups & 1.525 & 1 & 1.525 & 0.067 & 0.798 \\
Residual & 547.193 & 24 & 22.800 & & \\
Total & 548.718 & 25 & 21.949 & & 0.492 \\
\hline \multicolumn{7}{c}{ (Picture } & $\# 5)$ \\
Groups & 24.863 & 1 & 24.863 & 0.488 & \\
Residual & 1223.590 & 24 & 50.983 & & \\
Total & 1248.453 & 25 & 49.938 & & \\
\hline
\end{tabular}


TABLE VI

MEANS FOR AII SUBJECTS

\begin{tabular}{|c|c|c|}
\hline Picture & $\begin{array}{l}\text { ICW After Training } \\
\text { Pretested }\end{array}$ & $\begin{array}{l}\text { ICW After Training } \\
\text { Nonpretested }\end{array}$ \\
\hline \multicolumn{3}{|c|}{ (American Subjects) } \\
\hline 2 & 21.69 & 22.61 \\
\hline 3 & 24.05 & 23.64 \\
\hline 5 & 34.82 & 31.83 \\
\hline \multicolumn{2}{|c|}{ (International Subjects) } & $(n=18)$ \\
\hline 2 & 25.03 & 23.50 \\
\hline 3 & 22.15 & 22.68 \\
\hline 5 & 29.14 & 27.02 \\
\hline
\end{tabular}

Again, the means were not even systematically higher for pretested groups. From these data it is not plausible that pretested $\mathrm{Ss}^{\prime}$ posttest scores reflect different populations. Because no systematic differences were found between pretested and posttest-only ICW students in the preceding analyses, these groups were pooled for hypothesis testing in the subsequent phases of data analyses.

\section{NONEQUIVALENT POSTTEST-ONLY}

The third analysis dealt with measuring if there were any significant differences between students who received the ICW training $\left(\mathrm{O}_{2}+\mathrm{O}_{3}, \mathrm{O}_{6}+\mathrm{O}_{7}\right)$ and the general control samples $\left(\mathrm{O}_{4}+\mathrm{O}_{8}\right)$. Using separate variance estimates, 
four T-tests were computed for the American groups and four T-tests for the International groups based on photos 2, 3, and 5 data, and totals of photos 2, 3, and 5. See Tables VII and VIII for these results. 


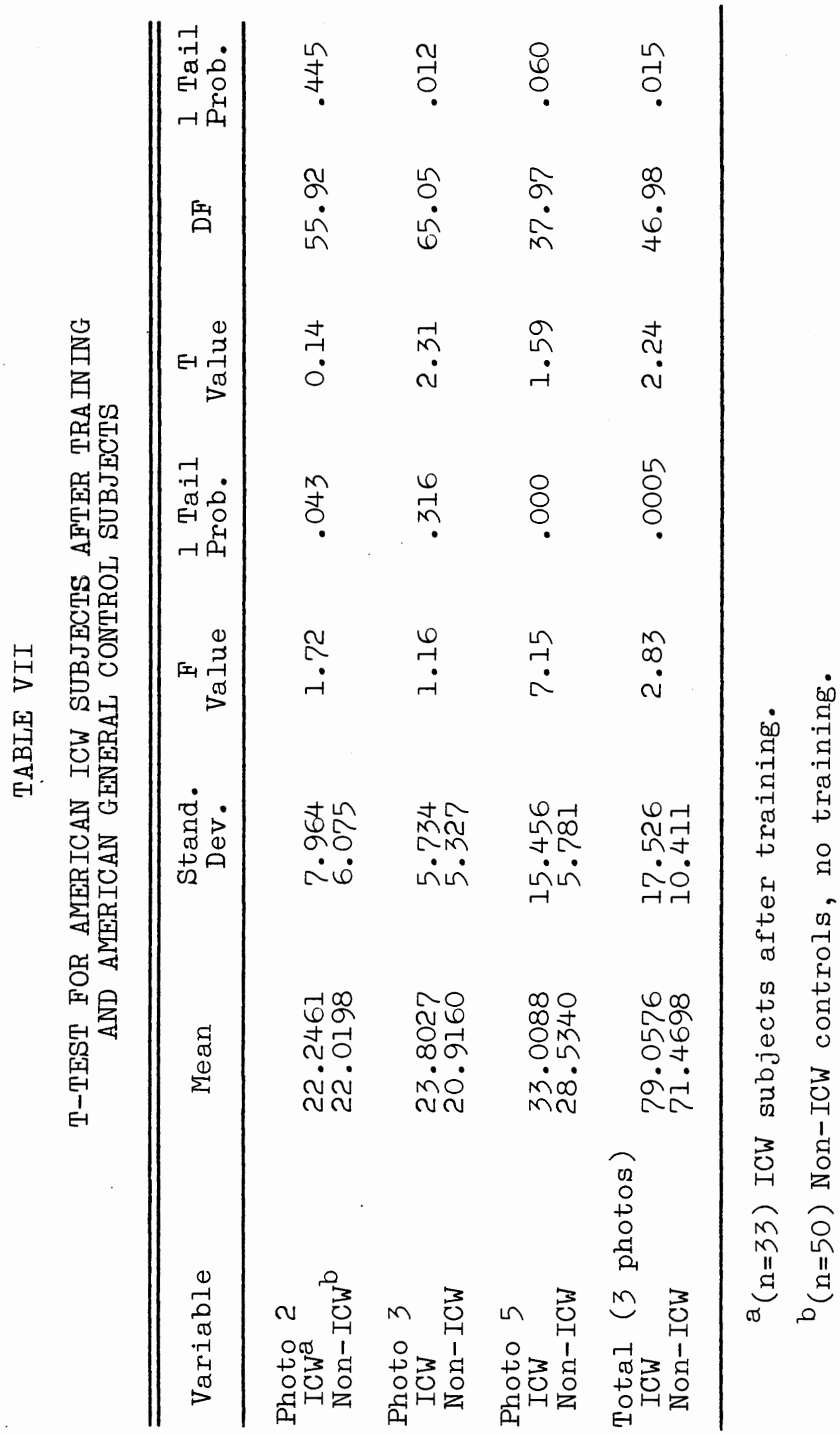


In Table VII it is interesting to note that the individual scores per photo showed no statistically significant difference for photo 2--Saudi Arabian and American student; significant difference for photo 3--Japanese and American student; and nearly statistically significant difference for photo 5--Black Libyan and American student.

Table VII also indicates that for American subjects, the ICW training resulted in significant difference for total scores for all three photos. Since sub-hypothesis 1 states:

After completing the ICW, American student subjects will demonstrate a decrease in culture-bound evaluation by exhibiting an increase in positive evaluations of an I/A student dyadic interaction as compared to their student peers with no ICW training, the results of the third phase of the data analyses--NonEquivalent Posttest-Only--strongly support this hypothesis in two of three photos by showing a significant difference for total scores in the predicted direction between American ICW subjects and non-ICW student peers. The next chapter will discuss these results in more depth.

Table VIII shows the total scores for all photos and scores for individual photos between post-ICW International subjects and their non-ICW student peers. 


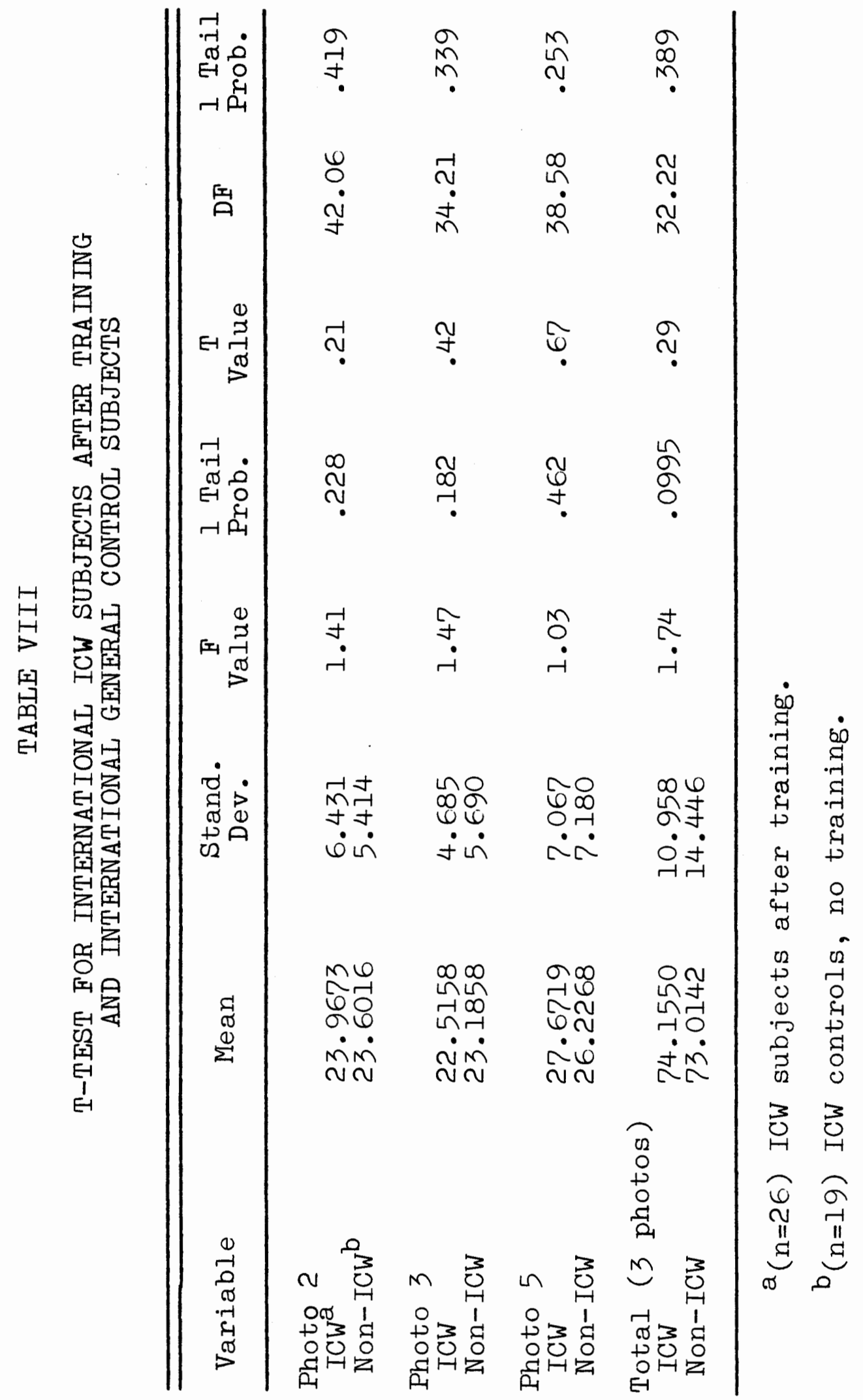


Table VIII indicates that for International subjects, ICW training showed no statistically significant differences for total score or any of the three photos' individual scores. Means for photos 2 and 5, and total score indicate a difference between the two groups in the predicted direction, although it is not statistically significant. However, photo 3 registered a difference opposite to the predicted direction. These results did not support sub-hypothesis 2 which states:

After completing the ICW, International student subjects will demonstrate a decrease in culture-bound evaluation by exhibiting an increase in positive evaluations of an I/A student dyadic interaction as compared to their student peers with no ICW training.

This means that even if slight differences were registered in the predicted direction for post-ICW International students, with exception of photo 3 , the differences were inconsequential, not approaching statistical significance. These results will be discussed in the next chapter.

\section{ONE GROUP PRETEST-POSTTEST}

The fourth major analysis measured if any significant change took place as a direct result of the ICW training in the two ICW groups $A$ and $D$, which were both pretested and posttested $\left(\mathrm{O}_{2}-\mathrm{O}_{1}, \mathrm{O}_{6}-\mathrm{O}_{5}\right)$. This analysis included 
subjects who were present during both the pretest and the posttest. Again, using separate variance estimates, four T-tests were computed for the American Ss and four T-tests for the International Ss. As before, comparisons were based on photos 2, 3, and 5 data, and totals of photos 2 , 3, and 5 data. See Tables IX and $X$ for these results. Table IX indicates differences, if any, between ICW American subjects before training as compared to after the training. Table $\mathrm{X}$ indicates differences, if any, between ICW International subjects before training as compared to after the training. 


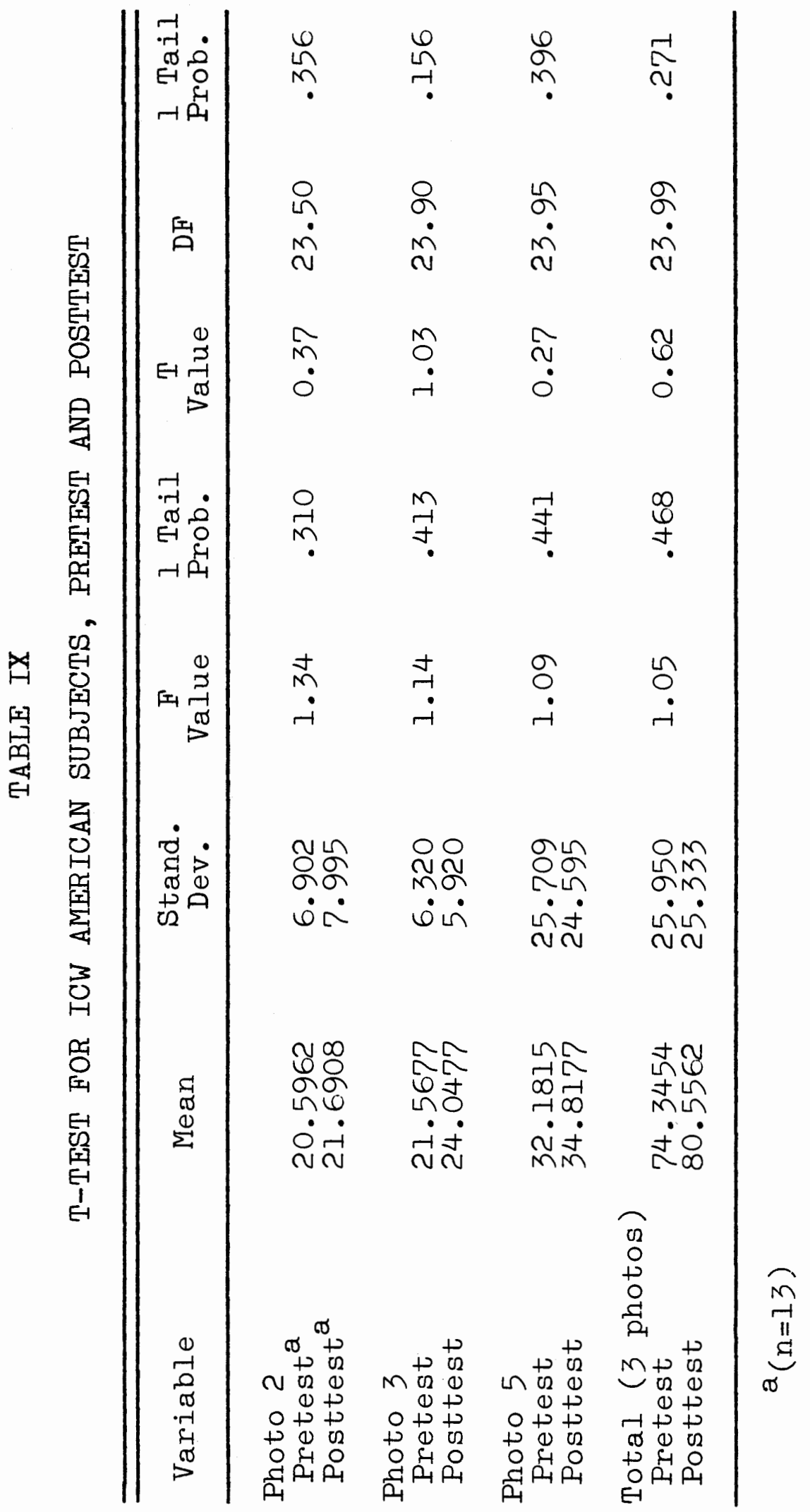




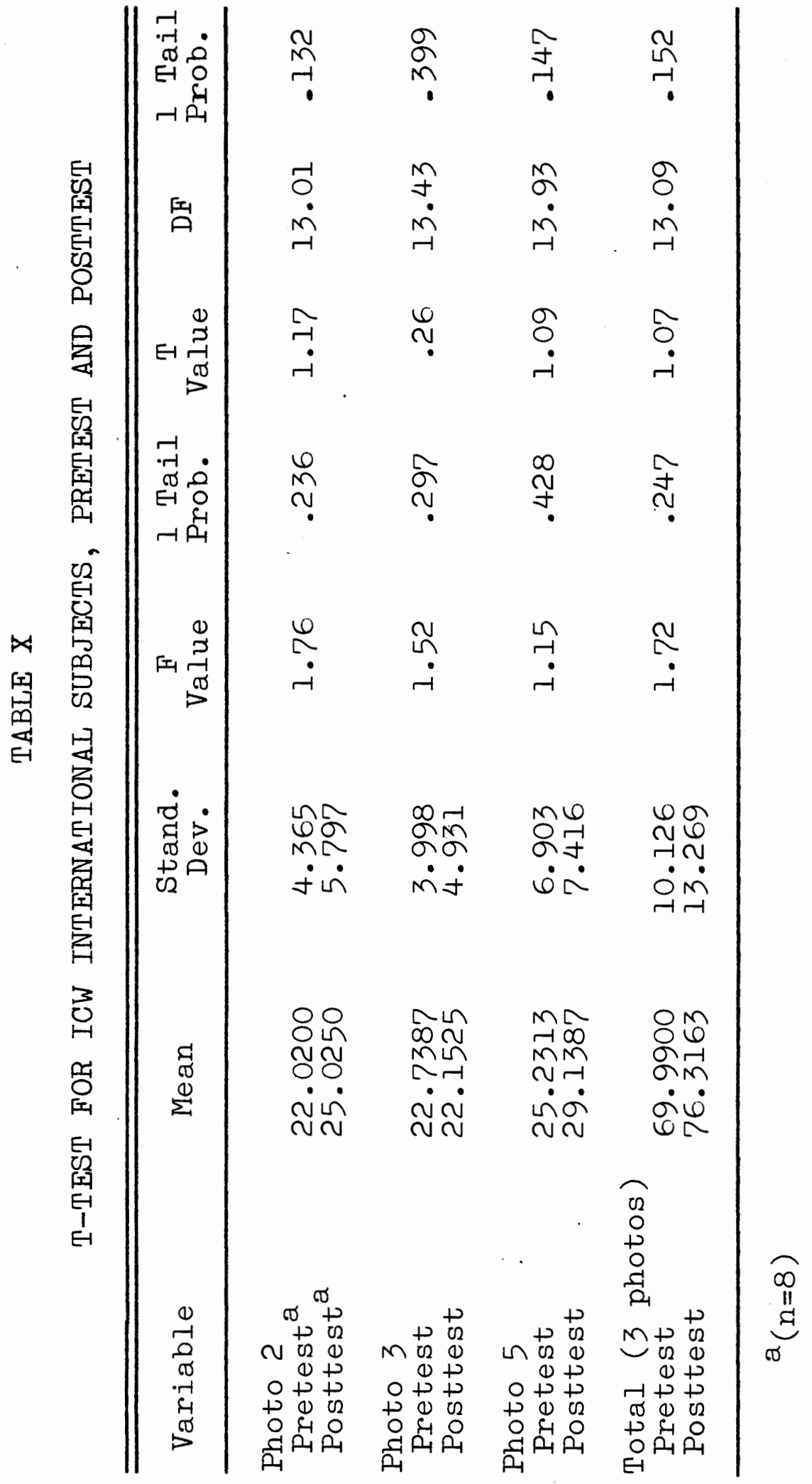


Table IX makes it evident that no significant differences for any of the three photos or total score were registered for ICW Americans as compared to before the training. However, the mean scores for all photos and total score indicate a change in the predicted direction, although these scores are not statistically significant. These results failed to confirm sub-hypothesis 3:

After completing the ICW, American student subjects will demonstrate a decrease in culture-bound evaluation by exhibiting an increase in positive evaluations of an I/A dyadic interaction as compared to before the ICW training.

Table $X$ shows that no significant differences for any of the three photos and total score were registered for ICW International subjects as compared to before the training. As before, the mean scores for photos 2, 5, and total score indicated a change in the predicted direction. These results failed to support sub-hypothesis 4: After completing the ICW, International student subjects will demonstrate a decrease in culture-bound evaluation by exhibiting an increase in positive evaluations of an I/A dyadic interaction as compared to before the ICW training.

\section{SUMMARY}

This chapter has presented the results of the study which investigated the ICW's affect on decreasing culture- 
bound evaluation. The results were presented in the order in which various data analyses were performed.

The first phase of the data analyses--Selection Bias-checked a potential sampling bias on the part of the subjects who opted to take the ICW by comparing American and International subjects before training with non-ICW subjects. The results established that there were minimal differences in evaluation between subjects who chose to enroll in the ICW and their non-ICW peers.

The second phase of the data analyses--Testing Effects--examined the potential testing effect on the students who were pretested with those that were not pretested. It was necessary to test to what extent the pretested group's posttest scores were inflated due to efforts of the pretest beyond any treatment effects. No statistically significant differences were found to exist between these groups for either American or International subjects. We can therefore assume that the pretest did not inflate the scores of the posttest.

The third phase of the data analyses--Nonequivalent Posttest-Only--assessed whether there were any significant differences between subjects who received the ICW training and the general control subjects. The results indicated that the ICW training evidenced less evaluation than nonICW American Ss, but failed to establish the same results 
for International subjects. No significant differences were indicated for these subjects.

The fourth phase of the data analyses--One Group Pretest-Posttest--measured if any significant change took place as a direct result of the ICW training in the two ICW groups which were both pretested and posttested. This analysis included subjects who were present during both the pretest and the posttest thereby reducing the test populations to thirteen American subjects and eight International subjects. No significant differences were registered for ICW American and International subjects as compared to before the ICW training. The last chapter will discuss the results and conclude the study. 


\section{CHAPTER V}

\section{CONCLUSION}

This chapter will explore the implications and applications of this study which has investigated the effect of the Intercultural Communication Workshop on decreasing culture-bound evaluation. The chapter will also address the main limitations of the study.

Hypotheses testing for ICW subjects before and after training indicates that no statistically significant differences were measured when comparing the scores from the first day of class to the scores on the last day of class. However, a slight change in the predicted direction was measured. This result may in part be attributable to the small sample size of only eight International subjects and thirteen American subjects. These small samples may make the results less valid.

Another consideration is the procedure used for computing test results which included both missing and unreliable adjectives. (These data were modified subsequent to the "First Impression Test" administration on the basis of the reliability study.) This procedure would decrease the likelihood of a Type I error--establishing that there are differences in evaluation as a result of the training 
provided by the ICW when actually none exist, and thereby reject the null hypothesis, and increase the likelihood of a Type II error--establishing that there are no differences in evaluation as a result of the ICW when actually differences indeed do exist, and thereby fail to reject the null hypothesis. This consideration could indicate that the training provided by the ICW influences all students in the direction of positive evaluation, but the procedures used by the present investigator failed to measure these differences.

What the study definitely indicates, based on the results from the Nonequivalent Posttest-Only hypotheses testing, is that the ICW training is effective for American subjects by influencing their attitudes toward an intercultural dyad in a positive direction. The results show a significant difference between American ICW subjects and the control non-ICW student peers in their evaluation of one photo, a nearly significant difference for a second photo, and a statistically significant total score difference in the predicted direction. The results do not support that such is the case for the International subjects even if a slight, but not statistically significant difference in a positive direction was registered.

It would be valuable to investigate if the results from this study could be repeated in another study. If the results were the same, they would serve as a foundation 
from which to establish hypotheses to possibly explain why and how American ICW subjects benefit in the way tested from the ICW training and why and how International subjects do not.

As possible explanations of these results, this section will offer several suggestions: the first one is that International students already may be more interculturally aware and sensitive in comparison to native subjects. Most of the International subjects in this study had spent quite some time in the United States to acquire necessary language skills for participation in the ICW. We are actually in the position to check greater initial positivity on the part of the International subjects by looking at Table III (p. 65). This shows mean scores before ICW training for all subjects. The table indicates that subjects enrolled in the ICW and their non-ICW student peers' mean scores are higher than for American ICW subjects and their non-ICW student peers, but only for picture 2 and 3. These pictures show a Saudi Arabian and a Japanese student in interaction with an American who is the same one in both pictures. When it comes to picture 5, however, the Americans overall show a much higher mean than the International subjects--the figures being 32.18 and 28.53 for the Americans, before ICW and no training respectively, and for International subjects--25.23 and 26.23. Picture 5 shows a Black Libyan in interaction with 
the American. The attitudes manifested toward this picture are actually a puzzle, since the mean scores are considerably higher for both International and American subjects compared to pictures 2 and 3 .

A future researcher might find it worthwhile to study the implied greater degree of intercultural sophistication on the part of the International students which the present study suggests because of these students' greater initial positivity. It would further be most interesting to study the overwhelming positive attitude manifested towards the Black Iibyan throughout the study. This becomes evident when looking at all ten tables and holds true for American and International students both.

Another reason which may explain why American subjects benefit from the ICW training, as measured in this study, while International students do not, may be that the ICW is an American concept, its origin and history are American, the particular ICW under investigation is also administered in an American university by American directors, and the workshop is mostly facilitated by Americans. Additionally, the makeup of each ICW group is usually half American students and half International students. Maybe it is simply not sufficient to be interculturally sophisticated, as both the directors and the facilitators definitely are, to reach such a heterogenous group of students as the ones enrolled in the ICW. The whole idea 
of learning through the format of group process is most likely foreign to the majority of the International students, and this group structure may be an element that seriously interferes with learning for these students. An interesting research project could be executed in this area of favorable learning climates and learning styles on the part of the International students versus American students.

A final note should be directed toward the investigator's decision to test for a decrease in negative culture-bound evaluation by an increase in positive evaluation. Since the ultimate goal of intercultural communication education and training is the ability to refrain from any culture-bound evaluation, a goal which most definitely is addressed by the ICW, it might have been more appropriate to test in some way a move to "nonevaluation." This study assumed that movement toward more positive evaluation is an interim step in developing a nonevaluative attitude. This assumption could be checked by comparing a direct study of nonevaluation to this study.

The previous pages have generated several suggested applications for future research which are implicated in the results of the present study. The chapter will now discuss some of the study's limitations.

There are several limitations to this study, and this investigator would venture to express that any study 
undertaking to measure change in intercultural attitudes is likely to have some limitations due to the complexity of the variables involved. One of the main limitations of this study is that "International students" or "International subjects" are not a homogenous group, but consisting of members from many different countries with at least as many differences between them as they individually have with Americans. However, the study would have been unwieldy and impossible to carry out, if each cultural group were to be treated as an entity. Therefore, it was decided to group students from various cultures into one manageable group called "International subjects."

As a theoretical field that includes skill development, intercultural communication training and education should have demonstrable lasting effects. This means that the training provided in the ICW should have influence beyond the time immediately after the course. Any study investigating the effect of intercultural communication training, therefore, ought to have a mechanism whereby it would be possible to measure if the training made any difference six months to one year after completion, or even after a longer time had passed. A limitation of the present study is that it does not have such a mechanism for a longitudinal follow-up.

Another limitation may be using the picture method to evaluate the success of the ICW. This method controlled 
variables in the testing situation, but did not get at any direct report of the behavior exhibited by the dyadic communicants in the intercultural interaction. A related limitation may be that the test depended upon the subjects' sense of evaluative connotations of the adjectives used. Although "clarity" of evaluative connotations was checked in the research procedures of this study, it may nevertheless be the case that Americans used adjectives more consistently, while International students with less American language facility may have been using the adjectives more randomly.

The present study has attempted to investigate the effect on decreasing culture-bound evaluation in intercultural communication through education and training with the special focus. being the ICW at Portland State University. Culture-bound evaluation, that is, the kind of evaluation which originates in ethnocentric viewpoints, is a serious topic which no one can afford to take lightly. If we do not take this topic seriously, our planet is likely to be extinguished in a nuclear holocaust. Culture-bound evaluation enters into our lives on a daily basis. We do not necessarily have to wait until we are involved in a face-to-face encounter with someone from another culture. Everyday exposure to world events through newspapers and television provides us with the opportunity to use culture-bound judgments. These judgments 
often color our perceptions and influence our communication.

An example of this influence and a possible explanation as to why the picture of the Saudi Arabian and the American failed statistical significance for the American ICW subjects in the Nonequivalent Posttest-Only, could be that the data collection occurred during winter and spring of 1980. During the same time period Iran held many Americans hostage. As will be remembered, the antiIranian sentiment was considerable during that time, and its influence may have counteracted the training and education of the ICW. American students may not be able to distinguish a Saudi Arabian from an Iranian and vice versa. That this was the reason behind the result of picture 2 can, of course, not be ascertained, but its possible influence should not be ignored.

This chapter has addressed some implications, applications, and limitations of the study investigating the ICW's affect on decreasing culture-bound evaluation. The results of the study are not conclusive, but they indicate that the ICW may be successful in decreasing culturebound evaluation for American subjects, but not for International subjects. Future research is obviously necessary and several directions for this have been expressed in the chapter. 


\section{SELECTED BIBLIOGRAPHY}

Barna, IaRay. "Stumbling Blocks in Intercultural Communication," in Intercultural Communication: A Reader. Edited by $\mathrm{I}$. Samovar and R. Porter. Belmont, CA: Wadsworth Publishing Company, 1982, 322-331.

Barnlund, Dean C. "Communication: The Context of Change," in Basic Readings in Communication Theory. Edited by C. David Mortensen. New York: Harper and Row, 1979, $6-24$.

Barnouw, Victor. An Introduction to Anthropology: Ethnology. Vol. II. Homewood, IL: The Dorsey Press, 1971.

Bateson, Gregory. Mind and Nature. New York: Bantam Books, E. P. Dutton, 1980 .

Bem, Daryl J. Beliefs, Attitudes and Human Affairs. Belmont, CA: Brooks/Cole Publishing Company, 1970.

Bennett, Milton. "Overcoming the Golden Rule: Sympathy and Empathy," in Communication Yearbook, \#3. Edited by Dan Nimmo. New Jersey: Transaction Books, 1979, $407-423$.

Brislin, Richard W. Cross-Cultural Encounters. New York: Pergamon Press, 1981.

Campbell, Donald T. and Stanley, Julian C. Experimental and Quasi-Experimental Designs for Research. Chicago: Rand McNally Company, 1972.

Civikly, Jean M. Messages: A Reader in Human Communication. West Hanover, MA: Random House, Inc., 1974.

Condon, John C. and Fathi, Yousef. An Introduction to Intercultural Communication. Indianapolis, IN: The Bobbs-Merrill Company, Inc., 1976.

Dawes, Robyn M. Fundamentals of Attitude Measurement. New York: Publishers John Wiley \& Sons, Inc., 1972.

Dewey, John and Dewey, Evelyn. Schools of Tomorrow. New York: E. P. Dutton \& Company, 1915.

Downie, N. M. and Starry, A. R. Descriptive and Inferiential Statistics. New York: Harper and Row, 1977. 
Gibb, Jack R. "Defensive Communication," in Basic Readings in Communication Theory. Eaited by $\mathrm{C}$. David Mortensen. New York: Harper and Row, 1979, 201-208.

Haggard, E. A. and Isaacs, K. S. "Micromomentary Facial Expressions as Indicators of Ego Mechanisms in Psychotherapy," in Methods of Research in Psychotherapy. New York: Meredith, 1966, p. 165.

Hall, Edward T. Beyond Culture. Garden City, NY: Anchor Books, Doubleday \& Company, Inc., 1977.

The Hidden Dimension. Garden City, NY: Anchor Books, Doubleday \& Company, Inc., 1969.

The Silent Language. Greenwich, CT: Fawcett Publications, Inc., 1967 .

Hastorf, Albert, Schneider, David, and Polefka, Judith. Person Perception. Redding, MA: Addison Wesley, 1970.

Heider, Fritz. The Psychology of Interpersonal Relations. New York: John Wiley \& Sons, 1958.

Homans, G. C. Social Behavior: Its Elementary Form. New York: Harcourt, Brace, 1961.

Hoopes, David S., ed. Readings in Intercultural Communication: The Intercultural Communication Workshop. Vol. I. University of Pittsburgh, Pittsburgh, PA: The Intercultural Communications Network. The Society for Intercultural Education, Training and Research, 1975.

and Rhinesmith, Stephen H. "The Learning Process in an Intercultural Setting," in Readings in Intercultural Communication. Vol. II. Edited by David S. Hoopes. University of Pittsburgh, Pittsburgh, PA: Regional Council for International Education, 1972.

Hopper, Robert and Whitehead, Jack I. Jr. Communication Concepts and Skills. New York: Harper and Row, 1979.

Hull, W. Frank IV. "The Cross-Cultural Interaction Workshop: Learning in International Education," in Readings in Intercultural Communication. Vol. II. Edited by David S. Hoopes. University of Pittsourgh, Pittsburgh, PA: Regional Council for International Education, 1972. 
Laing, Ronald D. The Politics of Experience. New York: Ballantine Books, Inc., 1971.

Phillipson, H., and Lee, A. R. Interpersonal Perception. New York: Perrenial Library, Harper and Row, Publishers, 1972.

Lee, Dorothy. Freedom and Culture. New York: PrenticeHall, Inc., 1959.

Marris, Peter. Loss and Change. Garden City, NY: Anchor Press, Doubleday \& Company, Inc., 1975.

Maslow, Abraham H. "Isomorphic Interrelationships," in The Human Dialogue. Edited by Floyd W. Matson and Ashley Montagu. New York: The Free Press, 196?, 195-206.

- Motivation and Personality. New York: Harper and Brothers, 1954.

Mehrabian, Albert. "Communication Without Words," in Basic Readings in Communication Theory. Edited by C. David Mortensen. New York: Harper and Row, 1979, 193-200.

Neff, Charles B. New Directions for Experimental Learning: Cross-Cultural Learning. Washington, D.C.: JosseyBass, Inc., 1981.

Newcomb, T. M. "An Approach to the Study of Communicative Act," Psychological Review, 60 (1953), 393-404.

Nie, Norman H., Hull, C. Hadlai, Jenkins, Jean G., Steinbrenner, Karin, and Bent, Dale H. Statistical Packages for the Social Sciences. 2nd ed. New York: McGraw Hill, Inc., 1975.

Postman, Neil and Weingartner, Charles. Linguistics: A Revolution in Teaching. New York: Dell Publishing Company, Inc., 1966.

Prosser, Michael H. The Cultural Dialogue: An Introduction to Intercultural Communication. Boston, MA: Houghton Mifflir. Company, 1978.

Rogers, Carl. On Becoming a Person. Boston, MA: Houghton Mifflin Company, 1961.

Rokeach, Milton. Beliefs, Attitudes, and Values. San Francisco: Jossey-Bass, 1968. 
Ruesch, M. D. and Bateson, Gregory. Communication: The Social Matrix of Society. New York: W. W. Norton and Company, 1968.

Samovar, Larry A. and Porter, Richard E. Intercultural Communication: A Reader. 2nd ed. Belmont, CA: Wadsworth Publishing Company, 1982.

Sapir, Edward. Selected Writings of Edward Sapir. Edited by David G. Mandelbaum. Berkeley, CA: Univ. of California Press, 1949.

Sherif, Muztafa. Social Interaction--Process and Products. Chicago: Aldine, 1967.

, and Hovland, C. I. "Judgmental Phenomena and Scales of Attitude Measurement: Placement of Items with Individual Choice of Number Categories," Journal of Abnormal Social Psychology, 48 (1953), 135-141.

Simon, Sidney B., Howe, Leland W., and Kirschenbaum, Howard. Values Clarification: A Handbook of Practical Strategies for Teachers and Students. New York: Hart Publishing Company, Inc., 1972.

Swenson, Clifford H. Jr. Introduction to Interpersonal Relations. Glenview, II: Scott, Foresman and Company, 1973.

Tyler, Sir Edward Burnett. Anthropology: An Introduction to the Study of Man and Civilization. New York: D. Appleton and Company, 1881.

Wallace, John A. "Educational Values of Experiential Education," in Beyond Experience: The Experiential Approach to Cross-Cultural Education. Edited by Donald Batchelder and Elizabeth G. Warner. Brattleboro, VT: The Experiment Press, 1977, 23-27.

Watzlawick, Paul, Beavin, Janet Helmick, and Jackson, Don D. Pragmatics of Human Communication: A Study of Interactional Patterns, Pathologies, and Paradoxes. New York: W. W. Norton \& Company, Inc., 1967.

Webster's Seventh New Collegiate Dictionary. Springfield, MA: G. and C. Merriam Company, Publishers, 1967.

White, Leslie A. and Dillingham, Beth. The Concept of Culture. Minneapolis: Burgess Publishing Company, 1973. 
APPENDIX A

DEF INIT ION OF TERMS 


\section{DEF INITION OF TERMS}

Culture, language, assumptions, beliefs, values, and attitudes form a cohesive, interrelated whole. It is often difficult to speak of one of these concepts without considering all or some of the others. An attempt to list these within a hierarchical structure also presents difficulties, since assumptions, beliefs, values, and attitudes are one's culture along with one's language. In spite of this I will below make such an attempt from the viewpoint of chronological socialization of a newborn infant:

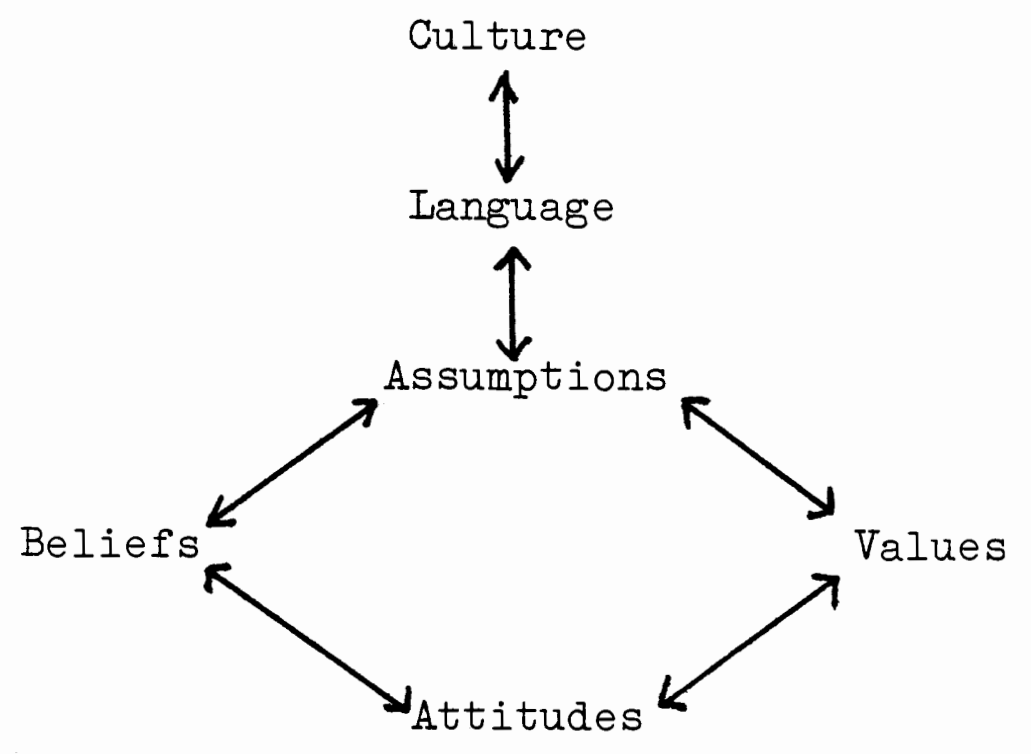

An infant is born into a given society with its own definite culture. Through socialization the infant learns the language which serves as the medium through which assumptions about the world around her are acquired. Assumptions lead to particular beliefs which form the bases 
for values. These constructs together underlie attitudes which often predispose one to act.

I realize that a hierarchical order of importance is indicated by the foregoing, but this is only done for the purpose of discussion. Further considerations of these concepts follow.

\section{Culture and Language}

Culture and language are viewed as an interrelated whole based upon theories by Boas in 1911, Sapir in 1931, and Whorf in 1932 (Samovar and Porter 1982, p. 152). It seems prudent to assume that communication is so intricately interwoven with culture that the two become indistinguishable.

\section{Assumptions}

To assume is defined by Webster as "To take for granted as true." One's culture then determines what is to be taken for granted about internal and external reality. Assumptions would come under Bem's zero-order beliefs which he also refers to as primitive beliefs of the fundamental kind:

We shall call primitive beliefs of this fundamental kind "zero-order" beliefs. They are the nonconscious axioms upon which our other beliefs are built (Bem 1970, p. 4).

Primitive beliefs are not questioned, and it is difficult to imagine alternatives to assumptions. 


\section{Beliefs}

Three definitions of belief are listed below:

A perceived relationship between the things or between something and a character of it.

Collectively, a man's belief composes his understanding of himself and his environment (Bem 1970, p. 4).

Conviction of the truth of some statement or the reality of some being or phenomenon . . .

(Webster 1967, p. 101).

Since it is possible to imagine an alternative to a belief, Bem (1970) calls constructs which fall in this category "first-order" beliefs:

Unlike zero-order beliefs, an individual is usually aware of his first-order beliefs because he can readily imagine alternatives to them (oranges could be square), but he is usually not aware of any inferential process by which they derive from zero-order beliefs ( $p .4)$.

From this one may conclude that "belief" is an esoteric construct which is difficult to define. For the present purpose "the conviction of perceived truth of any relationship between two things or between a thing and a characteristic of it" will suffice.

Values

A value is defined as a "primitive preference for or a positive attitude toward certain end states of existence (like equality, salvation, fulfillment or freedom)" (Bem 1970 , p. 17). The values one has are considered as "good" in opposition to other values which are considered "bad." 


\section{Attitudes}

An attitude predisposes one to act in certain ways (Samovar and Porter 1982, p. 9). Attitudes thereby underlie behavior.

In summary, culture and language make up one's bases from which to communicate. As noted earlier, from this intricate intertwining, assumptions are made about reality which lead to specific beliefs and values, and these beliefs and values seem to underlie attitudes which predispose an individual to act. All of these interactively comprise an individual's communication system. 


\section{APPENDIX B}

SYLLABUS FOR SPEECH 140 (THE ICW) 


\section{SYLLABUS FOR SPEECH 140 (THE ICW)}

\section{INTRODUCTION TO INTERCULTURAL COMMUNICATION ( INTERCULTURAL COMMUUNICATION WORKSHOP - ICW)}

Speech Communication 140

Spring, 1980
Mondays, 2-4 PM

Dr. Milton Bennett

Director

The purpose of this course is to allow International and American students to learn about each others' cultures, and to improve cultural adaptation and Intercultural communication skills. In the course, we will:

-discuss the basic concepts of intercultural communication

- examine differences between American culture and other cultures

-explore different ideas about families, friendship, and other customs

-learn communication techniques that are useful cross-culturally

Except for the first session and one additional large-group session, students will meet in small groups of ten or so. Each small group will be led by two facilitators who have been trained in leading intercultural groups. Questions about assignments and meetings should be directed first to your facilitators, and, if they cannot help, to the Director.

\section{Texts}

Intercultural Communicating (Brigham Young University) Survival Guide for Overseas Living (I. Robert Kohls)

Requirements

Weekly attendance at the workshop sessions. Attendance at the workshop is very important, since each individual makes a special contribution to the group. If in case of serious emergency, it is necessary to miss a meeting, each person should contact the group facilitator at home, and inform him or her of the absence, before the meeting. The absence must be made up by telephoning or meeting two other group members and interviewing them about the last meeting, getting detailed information about what took place. Then the student must write a journal about the meeting, based on that information. 
Weekly Journal. Each week, workshop members must submit a journal to the facilitators before the next meeting. The journal can be mailed to the facilitators no later than Thursday, or can be delivered to a campus mailbox no later than Friday. (Facilitators may set other dates for journals, however.) The journal will be shared among group members. If a group member for some special reason wishes to communicate privately in a journal, the member may mark the journal "closed" and it will not be shared.

The journal should not be a summary of the previous meeting. Rather, it should be a thoughtful comment on a topic or conversation from the last meeting, or it should be an expression of feeling about something that happened at that meeting. From time to time, facilitators may assign a topic for your journal.

Outside activity. During the quarter, your group will meet once for a potluck dinner at someone's house or apartment. The date will be decided by your group. Each person should bring some food to share with the group. It would be most interesting if the food was a "typical" dish from your country.

In addition to food, each person should bring to the evening meeting an object that you think is "representative" of something in your culture. The object could be clothing, a carving, a utensil, a religious object, or anything else. You should be prepared to explain the significance of the object to the group.

Reading. Read Survival Kit for Overseas Living by the third week of class. Read the whole book, including the appendices (except Appendix D). If you are not an American, simple read the book as if it were written for someone traveling overseas from your own culture. Nearly everything Kohls says is equally applicable to Arabs, Japanese, etc. traveling to the U.S. Occasionally, when Kohls talks about American values, you might substitute your own cultural values for comparison.

Read Intercultural Communicating by the fifth week of class. Read the whole book, except Appendix A.

Your facilitators will be directing you to use certain concepts from both these books in writing your journals. In addition, the Kohls book will be used as a basis for the final project.

Final Project. This project is a written paper, 5-? pages long, typed if possible (8-10 pages handwritten). Find one person from another culture that you would like to 
learn about. This person may be a member of your workshop group, but must be from a different culture from your own. Set up a time (at least one hour) to talk with this person. Then, before you meet with the person, answer the questions on page 80 (Grandparents Exercise) of Kohls for yourself. When you meet with the person, ask him or her the same questions from the exercise. Pay special attention to any differences between how you would teach your grandchildren and how the other person would teach his/her grandchildren.

Write your paper in three parts, based on the information from the meeting with the other person:

Part I: What are some major differences between the way you would teach your grandchildren and the way the other person (from a different culture) would teach his or her grandchildren? (Refer to the questions on p. 80 , Kohls.)

Part II: How does how you would teach your grandchildren relate to your own culture? How does the other person's teaching relate to his/her culture? (Here you should refer to the idea of "cultural values" discussed both in Kohls and in Intercultural Communicating.)

Part III: What are some communication problems that might arise between the grandchildren who have been taught these different things? As "communicative problems," you should consider how each grandchild might interpret and evaluate the other grandchild's behavior in a way that could cause misunderstanding. 


\section{APPENDIX C}

SYLLABUS FOR SPEECH 507 (INTERCULTURAL FACILITATION) 


\section{SYLIABUS FOR SPEECH 507 (INTERCULTURAL FACIIITATION)}

\section{D Intercultural Facilitating}

Dr. Milton Bennett

The purpose of this course is to train persons with backgrounds in intercultural communication and group leadership in the particular skills of leading intercultural communication workshops. Students will learn to apply intercultural communication concepts and group communication techniques to create a successful educational experience for a small group of American and International students. The graduate seminar will meet two hours per week for presentations, discussion of assigned reading and debriefing of workshop experiences.

The major project in this course is the responsibility for a group of 10-12 students for the entire quarter. Each facilitator will work with a partner; each pair will be responsible for implementing an existing syllabus and for developing several topics for their group, which meets once a week for two hours. Facilitators will read and comment on weekly journals and a final student project for the members of their workshop. At least one additional hour per week in addition to the two hours group time and two hours seminar time will be scheduled separately by cofacilitators for preparation time.

Reading

Prerequisite Reading (required reading for SP 140 course) The Survival Kit for Overseas Living by Robert Kohls Intercultural Communicating (Brigham Young University) Required Reading Group Development (2nd edition) by Leland Bradford Multicultural Education by Peggy Pusch Readings: The Intercultural Workshop, Vol. I, edited by David Hoopes

"Cofacilitating" by J. William Pfeiffer and John Jones "Processing Questions: An Aid to Completing the Learning Cycle" by B. Gaw

"Transition Shock" by Janet Bennett "Overcoming the Golden Rule" by Milton Bennett The Exercise Packet (to be provided in class) Additional handouts as distributed 
Assignments

The work in this course derives from many levels of teaching and learning, which we hope are integrated processes for class participants!

Each week, cofacilitators will plan and conduct the Speech 140 course, under the guidance of the instructors and the syllabus. Facilitators will review and comment on student journals; report to the seminar on their experiences; and prepare reading for the graduate seminar discussion. In addition, during the quarter, facilitators will complete a paper analyzing their group, and submit three reports on their group sessions, for the last three sessions of the quarter.

Attendance at both the seminar and the workshop components of the program is particularly essential; facilitators play a pivotal role in the group's development and in the direction of the graduate seminar.

\section{WEEKLY DIRECT IONS}

The fluidity of this course is an important aspect of the learning involved, and this schedule of events is a guideline which has inherent in it the flexibility to change and redirect. Our experiences conducting intercultural programs provide insight into structuring such a course; the nature of intercultural dialogue necessitates that those insights remain adaptable and tentative!

Week One

Introduction to the Course; division of groups

Seminar: Planning Introduction sessions; overview of course; requirements

Reading: Hoopes.pg. 2-5.4; begin Survival Kit and Intercultural Communicating "Cofacilitating" article

Week Two

Student self-introductions and goal setting

Seminar: Learning to conduct group exercises: the D.I.E. exercise

Reading: Complete all Survival Kit and Intercultural Communicating; Hoopes pg. 54-102; "Processing Questions" article

Week Three

The Description, Interpretation and Evaluation Exercise

Seminar: Preparation for BAFA BAFA; theory of culture shock

Reading: Hoopes pg. 103-138; Bradford (selected readings) and "Transition Shock" article 
Week Four

BAFA BAFA

Seminar: Preparation for nonverbal; listening exercises; levels of adaptation to culture

Reading: Bradford (selected readings) and Iuce (selected reading)

Week Five

Iistening Exercises/Nonverbal

Seminar: Values Clarification/Cultural Topics Exercise

Reading: Bradford (selected readings) and Iuce (selected reading)

Week Six

Selection: cultural topics/values clarification/nonverbal Seminar: Group diagnosis

Reading: Bradford (selected reading) and Luce (selected reading )

Week Seven, Eight, and Nine

Facilitator planned activities and discussions

Seminar: Class reports due; small group skills; development model of the ICW: reentry theory

Reading: Complete all reading

Week Ten

Famous Artists Exercise

Seminar: Final analysis 
APPEINDIX D

FIRST IMPRESSION TEST 


\section{FIRST IMPRESSION TEST}

You will be shown a picture of two people in a conversation. We will refer to the people as A and B. Don't worry about what they are saying. Instead, imagine what each one is thinking the other one is like.

Please turn to the attached list and choose 3 words for each student in the picture that best describe what each one is thinking the other one is like and complete the sentences below. Do not use words which are not on the list.

Picture no. I:
A thinks the other person is
B "
" $"$
"

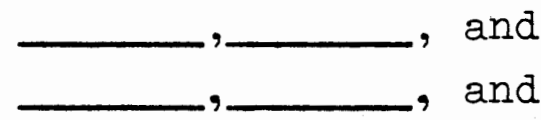

Picture no. 2:

A thinks the other person is

B "

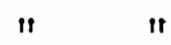

it

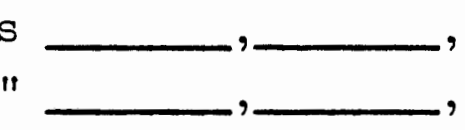

and and

Picture no. 3:

A thinks the other person is

B "

" $"$

it

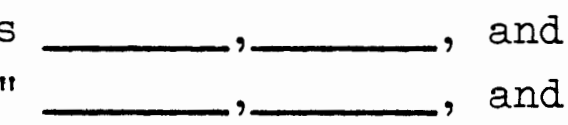

Picture no. 4:

A thinks the other person is

B "

" $"$

"

it

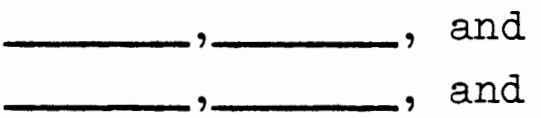

Picture no. 5:

A thinks the other person is

B "

it

11

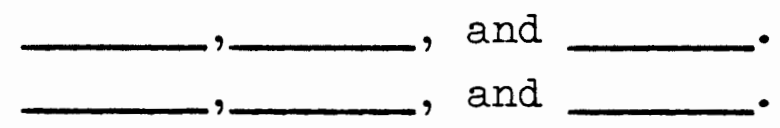


Shy

Talkative

Creative

False

Clever

Interesting

Firm

Dependable

Friendly

Believable

Kind

Surprised

Jealous

Cautious

Iazy

Studious

Rude

Unfriendly

Weak

Dangerous

Critical

Realistic

Slow

Quick

Brave

Colorful

Careless

Impolite

Dirty

Practical 


\section{APPENDIX E}

RATING ADJECTIVES ON A SEVEN TO ONE CONTINUUM 
RATING ADJECTIVES ON A SEVEN TO ONE CONTINUUM

If you used this word to describe another person, would you mean to be complimenting or criticizing him or her?

How positive or negative is this word?

Very Very Positive Negative $7 \in 5 \quad 4 \quad 3 \quad 2 \quad 1$

1. Rude

2. Jealous

3. Corrupt

4. Assertive

5. Colorful

6. Imaginative

7. Friendly

8. Serious

9. Cautious

10. Thrifty

11. Indifferent

12. Cheerful

13. Modest

14. Impolite

15. Intimate

16. Unfriendly

17. Quick

18. Brave $\begin{array}{lllllll}7 & 6 & 5 & 4 & 3 & 2 & 1\end{array}$

$7 \in 54321$

76543321

7654321

7654321

7654321

7654321

$\begin{array}{lllllll}7 & 6 & 5 & 4 & 3 & 2 & 1\end{array}$

$\begin{array}{lllllll}7 & 6 & 5 & 4 & 3 & 2 & 1\end{array}$

7654321

$\begin{array}{lllllll}7 & 6 & 5 & 4 & 3 & 2 & 1\end{array}$

7654321

7654321

7654321

7654321

7654321

7654321

7654321 
19. Curious

20. Talkative

21. Shy

22. Patient

23. Studious

24. Weak

25. Dirty

26. Clever

27. Iazy

28. Dependable

29. Kind

30. Violent

31. Firm

32. Loyal

33. Believable

34. Loud

35. Dangerous

36. Trustworthy

37. Creative

38. Realistic

39. Generous

40. Interesting

41. Rich

42. Careless

43. Shrewd

44. Surprised $\begin{array}{lllllll}7 & 6 & 5 & 4 & 3 & 2 & 1\end{array}$

$\begin{array}{lllllll}7 & 6 & 5 & 4 & 3 & 2 & 1\end{array}$

7654321

7654321

7654321

7654321

7654321

7654321

$7 \in 54321$

7654321

$7 \in 54321$

$7 \in 54321$

7654321

7654321

7654321

7654321

7654321

$7 \in 54321$

7654321

7654321

7654321

7654321

7654321

7654321

7654321

7654321 
111

45. Slow

46. Spontaneous

47. Thorough

48. Critical

49. Practical

50. Idealistic

51. False

52. Truthful $\begin{array}{lllllll}7 & 6 & 5 & 4 & 3 & 2 & 1\end{array}$

7654321

$\begin{array}{lllllll}7 & 6 & 5 & 4 & 3 & 2 & 1\end{array}$

$\begin{array}{lllllll}7 & 6 & 5 & 4 & 3 & 2 & 1\end{array}$

$\begin{array}{lllllll}7 & 6 & 5 & 4 & 3 & 2 & 1\end{array}$

$\begin{array}{lllllll}7 & 6 & 5 & 4 & 3 & 2 & 1\end{array}$

$\begin{array}{lllllll}7 & 6 & 5 & 4 & 3 & 2 & 1\end{array}$

$\begin{array}{lllllll}7 & 6 & 5 & 4 & 3 & 2 & 1\end{array}$ 
Nationality

Level in ESL

If you used this word to describe another person, would you mean to be complimenting (saying something positive) or criticizing (saying something negative) him or her?

How sure are you about what this word means?

Very

sure

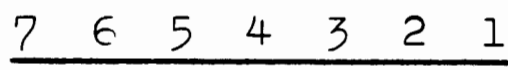

How positive or negative is this word?
1. Rude

2. Jealous

3. Corrupt

4. Assertive

5. Colorful

6. Imaginative

7. Friendly

8. Serious

9. Cautious

10. Thrifty

11. Indifferent

12. Cheerful

13. Modest

14. Impolite

15. Intimate

16. Unfriendly

17. Quick
$76 \begin{array}{lllllllllllll}7 & 6 & 4 & 3 & 2 & 1 & 7 & 6 & 5 & 4 & 3 & 2 & 1\end{array}$ $76 \begin{array}{lllllllllllll}7 & 6 & 4 & 3 & 2 & 1 & 7 & 6 & 5 & 4 & 3 & 2 & 1\end{array}$ $\begin{array}{llllllllllllll}7 & 6 & 5 & 4 & 3 & 2 & 1 & 7 & 6 & 5 & 4 & 3 & 2 & 1\end{array}$

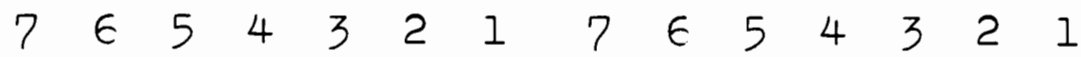
$\begin{array}{llllllllllllll}7 & 6 & 5 & 4 & 3 & 2 & 1 & 7 & 6 & 5 & 4 & 3 & 2 & 1\end{array}$ $\begin{array}{llllllllllllll}7 & 6 & 5 & 4 & 3 & 2 & 1 & 7 & 6 & 5 & 4 & 3 & 2 & 1\end{array}$ $\begin{array}{llllllllllllll}7 & 6 & 5 & 4 & 3 & 2 & 1 & 7 & 6 & 5 & 4 & 3 & 2 & 1\end{array}$ $\begin{array}{llllllllllllll}7 & 6 & 5 & 4 & 3 & 2 & 1 & 7 & 6 & 5 & 4 & 3 & 2 & 1\end{array}$ $\begin{array}{llllllllllllll}7 & 6 & 5 & 4 & 3 & 2 & 1 & 7 & 6 & 5 & 4 & 3 & 2 & 1\end{array}$ $76 \begin{array}{lllllllllllll}7 & 6 & 4 & 3 & 2 & 1 & 7 & 6 & 5 & 4 & 3 & 2 & 1\end{array}$ $76554 \quad \begin{array}{lllllllllll}7 & 6 & 5 & 1 & 7 & 6 & 5 & 4 & 3 & 2 & 1\end{array}$ $\begin{array}{llllllllllllll}7 & 6 & 5 & 4 & 3 & 2 & 1 & 7 & 6 & 5 & 4 & 3 & 2 & 1\end{array}$ $\begin{array}{llllllllllllll}7 & 6 & 5 & 4 & 3 & 2 & 1 & 7 & 6 & 5 & 4 & 3 & 2 & 1\end{array}$ $\begin{array}{llllllllllllll}7 & 6 & 5 & 4 & 3 & 2 & 1 & 7 & 6 & 5 & 4 & 3 & 2 & 1\end{array}$ $76 \begin{array}{lllllllllllll}7 & 6 & 4 & 3 & 2 & 1 & 7 & 6 & 5 & 4 & 3 & 2 & 1\end{array}$ $\begin{array}{llllllllllllll}7 & 6 & 5 & 4 & 3 & 2 & 1 & 7 & 6 & 5 & 4 & 3 & 2 & 1\end{array}$ $\begin{array}{llllllllllllll}7 & 6 & 5 & 4 & 3 & 2 & 1 & 7 & 6 & 5 & 4 & 3 & 2 & 1\end{array}$ 
113

18. Brave

19. Curious

20. Talkative

21. Shy

22. Patient

23. Studious

24. Weak

25. Dirty

26. Clever

27. Lazy

28. Dependable

29. Kind

30. Violent

31. Firm

32. Loyal

33. Dangerous

34. Loud

35. Believable $76 \begin{array}{lllllllllllll} & 6 & 4 & 3 & 2 & 1 & 7 & 6 & 5 & 4 & 3 & 2 & 1\end{array}$

36. Trustworthy $76 \in \begin{array}{lllllllllllll} & 7 & 4 & 3 & 2 & 1 & 7 & 6 & 5 & 4 & 3 & 2 & 1\end{array}$

37. Creative $7 \in 54 \quad 321 \quad 7 \quad 6 \quad 544321$

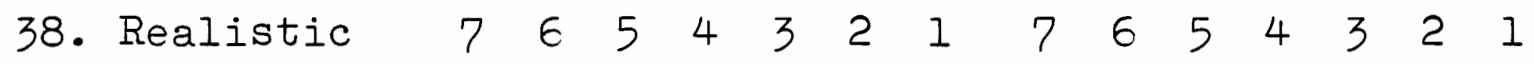

39. Generous $76 \begin{array}{lllllllllllll} & 6 & 4 & 3 & 2 & 1 & 7 & 6 & 5 & 4 & 3 & 2 & 1\end{array}$

40. Interesting $76 \begin{array}{lllllllllllll} & 6 & 4 & 3 & 2 & 1 & 7 & 6 & 5 & 4 & 3 & 2 & 1\end{array}$

41. Rich

42. Careless

43. Shrewd

$\begin{array}{llllllllllllll}7 & 6 & 5 & 4 & 3 & 2 & 1 & 7 & 6 & 5 & 4 & 3 & 2 & 1\end{array}$

$\begin{array}{llllllllllllll}7 & 6 & 5 & 4 & 3 & 2 & 1 & 7 & 6 & 5 & 4 & 3 & 2 & 1\end{array}$

$\begin{array}{llllllllllllll}7 & 6 & 5 & 4 & 3 & 2 & 1 & 7 & 6 & 5 & 4 & 3 & 2 & 1\end{array}$

$\begin{array}{llllllllllllll}7 & 6 & 5 & 4 & 3 & 2 & 1 & 7 & 6 & 5 & 4 & 3 & 2 & 1\end{array}$

$\begin{array}{llllllllllllll}7 & 6 & 5 & 4 & 3 & 2 & 1 & 7 & 6 & 5 & 4 & 3 & 2 & 1\end{array}$

$76 \begin{array}{lllllllllllll}7 & 5 & 4 & 3 & 2 & 1 & 7 & 6 & 5 & 4 & 3 & 2 & 1\end{array}$

$76 \begin{array}{lllllllllllll}7 & 6 & 3 & 2 & 1 & 7 & 6 & 5 & 4 & 3 & 2 & 1\end{array}$

$\begin{array}{llllllllllllll}7 & 6 & 5 & 4 & 3 & 2 & 1 & 7 & 6 & 5 & 4 & 3 & 2 & 1\end{array}$

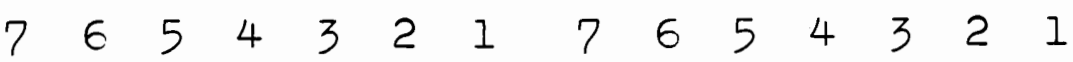

$\begin{array}{llllllllllllll}7 & 6 & 5 & 4 & 3 & 2 & 1 & 7 & 6 & 5 & 4 & 3 & 2 & 1\end{array}$

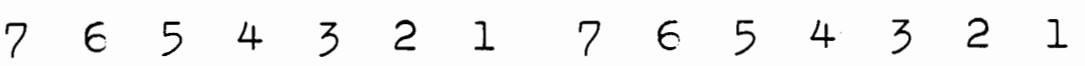

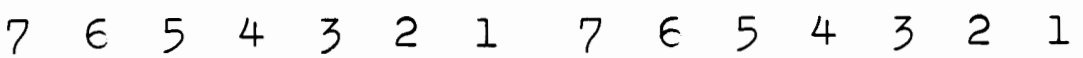

$\begin{array}{llllllllllllll}7 & 6 & 5 & 4 & 3 & 2 & 1 & 7 & 6 & 5 & 4 & 3 & 2 & 1\end{array}$

$765432176 \quad 6 \quad 544321$

$\begin{array}{llllllllllllll}7 & 6 & 5 & 4 & 3 & 2 & 1 & 7 & 6 & 5 & 4 & 3 & 2 & 1\end{array}$

$\begin{array}{llllllllllllll}7 & 6 & 5 & 4 & 3 & 2 & 1 & 7 & 6 & 5 & 4 & 3 & 2 & 1\end{array}$

$7654325176 \begin{array}{lllllll}7 & 6 & 5 & 5 & 3 & 2 & 1\end{array}$

$\begin{array}{llllllllllllll}7 & 6 & 5 & 4 & 3 & 2 & 1 & 7 & 6 & 5 & 4 & 3 & 2 & 1\end{array}$

$76 \begin{array}{lllllllllllll}7 & 6 & 4 & 3 & 2 & 1 & 7 & 6 & 5 & 4 & 3 & 2 & 1\end{array}$

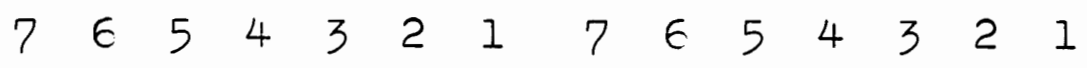


114

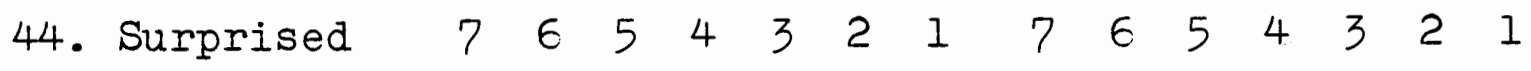

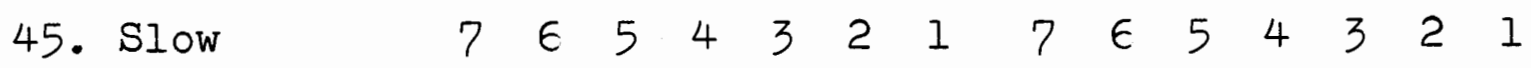

46. Spontaneous $766 \begin{array}{llllllllllll}5 & 4 & 3 & 2 & 1 & 7 & 6 & 5 & 4 & 3 & 2 & 1\end{array}$

47. Thorough $766 \begin{array}{cccccccccccc} & 7 & 3 & 2 & 1 & 7 & 6 & 5 & 4 & 3 & 2 & 1\end{array}$

48. Critical $76 \begin{array}{cccccccccccc}5 & 4 & 3 & 2 & 1 & 7 & 6 & 5 & 4 & 3 & 2 & 1\end{array}$

49. Practical $7 \in 6 \begin{array}{llllllllllll}5 & 4 & 3 & 2 & 1 & 7 & 6 & 5 & 4 & 3 & 2 & 1\end{array}$

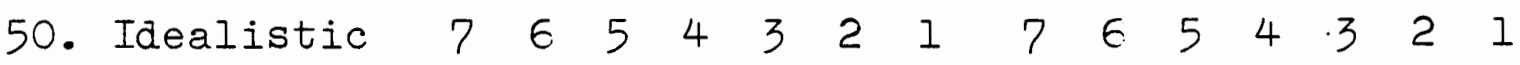

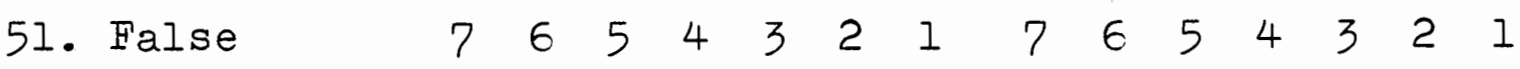

52. Truthfui $76 \begin{array}{lllllllllllll}7 & 6 & 4 & 3 & 2 & 1 & 7 & 6 & 5 & 4 & 3 & 2 & 1\end{array}$ 
APPENDIX F

SCORING AND COMPUTING ADJECTIVES 


\section{SCORING AND COMPUTING ADJECTIVES}

Below is a visual representation of computing an average value per adjective.

\#1 Rude

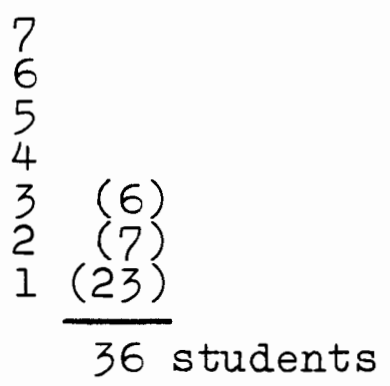

$$
\begin{aligned}
& =18 \\
& =14 \\
& =23 \\
& \hline 55
\end{aligned}
$$

$55: 36=1.53$ students

\#2 Jealous

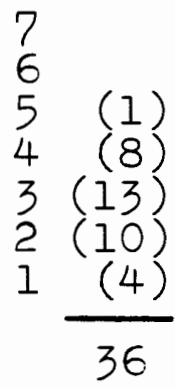

$$
\begin{aligned}
& =5 \\
& =32 \\
& =39 \\
& =20 \\
& =\frac{4}{100} \quad 100: 36=2.78
\end{aligned}
$$

\#3 Cormupt

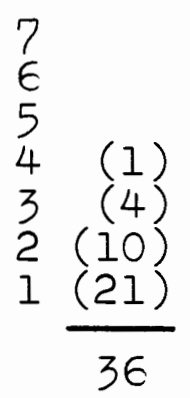

$$
\begin{aligned}
& =4 \\
& =12 \\
& =20 \\
& =\frac{21}{57} \quad 57: 36=1.58
\end{aligned}
$$


APPENDIX G

THIRTY SCALED ADJECTIVES 


\section{THIRTY SCALED ADJECTIVES}

Positive adjectives

\section{INTERNAT IONAI \\ SUBJECTS}

Colorful

Friendly

Quick

Brave

Studious

Clever

Kind

Believable

Creative

Realistic

Interesting

Practical

Neutral adjectives

Cautious

Talkative

Shy

Firm

Surprised

Critical

Dependable
4.62

3.79

3.12

4.73

4.97

3.64

3.92
6.17

6.51

5.43

6.09

5.41

6.28

6.43

5.44

6.06

5.43

6.46

5.69

AMERICAN SUBJECTS

5.78

6.78

5.28

5.86

5.67

5.44

6.83

5.69

6.61

5.42

6.19

5.14
4.42

4.17

3.58

4.86

4.39

3.19

3.83 
Negative adiectives

\section{INTERNAT IONAI SUBJECTS \\ AMERICAN \\ SUBJECTS}

Rude

Jealous

Impolite

Unfriendly

Weak

Dirty

Iazy

Dangerous

Careless

False

Slow
1.94

2.68

1.84

1.51

2.05

1.59

1.76

1.66

2.95

2.00

2.41
1.53

2.78

1.89

2.17

2.78

1.86

1.89

1.78

2.36

1.94

2.39 


\section{APPENDIX H}

CORRELATIONAI STUDY FOR RATING ADJECTIVES ON A SEVEN TO ONE CONTINUUM 
CORRELATIONAL STUDY FOR RATING ADJECTIVES

ON A SEVEN TO ONE CONT INUUTM

Below is the form used in the reliability study:

If you used this word to describe another person, would you mean to be complimenting (saying something positive) or criticizing (saying something negative) him or her?

How positive or negative is this word?

Very positive negative

\begin{tabular}{lllllll}
7 & 6 & 5 & 4 & 3 & 2 & 1 \\
\hline
\end{tabular}

1. Jealous

$\begin{array}{lllllll}7 & 6 & 5 & 4 & 3 & 2 & 1\end{array}$

2. Shy

$\begin{array}{lllllll}7 & 6 & 5 & 4 & 3 & 2 & 1\end{array}$

3. Clever

7654321

4. False

$\begin{array}{lllllll}7 & 6 & 5 & 4 & 3 & 2 & 1\end{array}$

5. Unfriendly

$\begin{array}{lllllll}7 & 6 & 5 & 4 & 3 & 2 & 1\end{array}$

6. Impolite

7654321

7. Quick

8. Kind

$\begin{array}{lllllll}7 & 6 & 5 & 4 & 3 & 2 & 1\end{array}$

9. Rude

$\begin{array}{lllllll}7 & 6 & 5 & 4 & 3 & 2 & 1\end{array}$

10. Creative

$\begin{array}{lllllll}7 & 6 & 5 & 4 & 3 & 2 & 1\end{array}$

11. Careless

$7 \in 54321$

12. Dangerous

$\begin{array}{lllllll}7 & 6 & 5 & 4 & 3 & 2 & 1\end{array}$

13. Surprised

$\begin{array}{lllllll}7 & 6 & 5 & 4 & 3 & 2 & 1\end{array}$

14. Talkative

7654321

15. Friendly

$\begin{array}{lllllll}7 & 6 & 5 & 4 & 3 & 2 & 1\end{array}$

16. Dirty

$\begin{array}{lllllll}7 & 6 & 5 & 4 & 3 & 2 & 1\end{array}$

17. Firm

18. Slow

$\begin{array}{lllllll}7 & 6 & 5 & 4 & 3 & 2 & 1\end{array}$

19. Brave

$\begin{array}{lllllll}7 & 6 & 5 & 4 & 3 & 2 & 1\end{array}$

20. Practical

$\begin{array}{lllllll}7 & 6 & 5 & 4 & 3 & 2 & 1\end{array}$

21. Studious

$\begin{array}{lllllll}7 & 6 & 5 & 4 & 3 & 2 & 1\end{array}$

$\begin{array}{lllllll}7 & 6 & 5 & 4 & 3 & 2 & 1\end{array}$

$\begin{array}{lllllll}7 & 6 & 5 & 4 & 3 & 2 & 1\end{array}$ 
22. Lazy

23. Colorful

24. Believable

25. Critical

26. Realistic

27. Weak

28. Interesting

29. Cautious

30. Dependable $\begin{array}{lllllll}7 & 6 & 5 & 4 & 3 & 2 & 1\end{array}$

$\begin{array}{lllllll}7 & 6 & 5 & 4 & 3 & 2 & 1\end{array}$

7654321

$\begin{array}{lllllll}7 & 6 & 5 & 4 & 3 & 2 & 1\end{array}$

$\begin{array}{lllllll}7 & 6 & 5 & 4 & 3 & 2 & 1\end{array}$

$\begin{array}{lllllll}7 & 6 & 5 & 4 & 3 & 2 & 1\end{array}$

$\begin{array}{lllllll}7 & 6 & 5 & 4 & 3 & 2 & 1\end{array}$

7654321

$\begin{array}{lllllll}7 & 6 & 5 & 4 & 3 & 2 & 1\end{array}$ 
RELIABIIITY FOR AMERICAN STUDENTS

\begin{tabular}{|c|c|c|c|}
\hline & Correlation & Mean & St. Dev. \\
\hline Jealous & .76 & $\begin{array}{l}2.55 \\
2.33\end{array}$ & $\begin{array}{l}.96 \\
.82\end{array}$ \\
\hline Clever & .65 & $\begin{array}{l}5.50 \\
5.50\end{array}$ & $\begin{array}{l}.83 \\
.83\end{array}$ \\
\hline False & .44 & $\begin{array}{l}2.28 \\
2.06\end{array}$ & $\begin{array}{l}1.15 \\
1.08\end{array}$ \\
\hline Unfriendly & .76 & $\begin{array}{l}2.22 \\
2.17\end{array}$ & $\begin{array}{r}1.08 \\
.83\end{array}$ \\
\hline Impolite & .46 & $\begin{array}{l}2.06 \\
1.77\end{array}$ & $\begin{array}{r}1.02 \\
.85\end{array}$ \\
\hline Quick & .60 & $\begin{array}{l}5.67 \\
5.33\end{array}$ & $\begin{array}{l}.88 \\
.94\end{array}$ \\
\hline Kind & .78 & $\begin{array}{l}6.39 \\
6.33\end{array}$ & $\begin{array}{l}.76 \\
.82\end{array}$ \\
\hline Rude & .59 & $\begin{array}{l}1.44 \\
1.50\end{array}$ & $\begin{array}{l}.69 \\
.68\end{array}$ \\
\hline Creative & .61 & $\begin{array}{l}6.44 \\
6.00\end{array}$ & $\begin{array}{l}.83 \\
.88\end{array}$ \\
\hline Careless & .67 & $\begin{array}{l}2.78 \\
2.56\end{array}$ & $\begin{array}{l}.85 \\
.90\end{array}$ \\
\hline Dangerous & .58 & $\begin{array}{l}2.39 \\
1.89\end{array}$ & $\begin{array}{r}1.06 \\
.87\end{array}$ \\
\hline Surprised & .65 & $\begin{array}{l}4.17 \\
4.17\end{array}$ & $\begin{array}{l}.50 \\
.60\end{array}$ \\
\hline Talkative & .51 & $\begin{array}{l}4.06 \\
3.94\end{array}$ & $\begin{array}{r}.91 \\
.85\end{array}$ \\
\hline Friendly & .71 & $\begin{array}{l}5.94 \\
6.05\end{array}$ & $\begin{array}{l}.70 \\
.78\end{array}$ \\
\hline Dirty & .40 & $\begin{array}{l}2.44 \\
2.39\end{array}$ & $\begin{array}{r}.96 \\
1.01\end{array}$ \\
\hline Firm & .45 & $\begin{array}{l}5.00 \\
4.83\end{array}$ & $\begin{array}{l}.81 \\
.90\end{array}$ \\
\hline Slow & .47 & $\begin{array}{l}3.28 \\
3.33\end{array}$ & $\begin{array}{r}1.10 \\
.58\end{array}$ \\
\hline Brave & .71 & $\begin{array}{l}5.83 \\
5.83\end{array}$ & $\begin{array}{l}.96 \\
.82\end{array}$ \\
\hline
\end{tabular}




$\begin{array}{lrrr}\text { Practical } & .65 & 5.29 & .82 \\ & & 5.29 & .82 \\ \text { Lazy } & .93 & 2.65 & .90 \\ & & 2.65 & .90 \\ \text { Colorful } & .58 & 5.78 & 1.18 \\ \text { Critical } & & 5.56 & 1.06 \\ & .59 & 4.00 & 1.20 \\ \text { Weak } & & 3.83 & 1.01 \\ & .55 & 2.67 & 1.00 \\ \text { Interesting } & & 2.61 & .68 \\ & .47 & 5.83 & 1.01 \\ \text { Cautious } & & 5.67 & .82 \\ & .58 & 4.22 & .71 \\ \text { Dependable } & & 4.22 & .42 \\ & .54 & 6.33 & .75 \\ & & 6.27 & .73\end{array}$


RELIABIIITY FOR INTERNATIONAL STUDENTS

\begin{tabular}{|c|c|c|c|}
\hline & Correlation & Mean & St. Dev. \\
\hline Jealous & .82 & $\begin{array}{l}3.17 \\
2.96\end{array}$ & $\begin{array}{l}1.25 \\
1.02\end{array}$ \\
\hline Clever & .81 & $\begin{array}{l}6.04 \\
6.04\end{array}$ & $\begin{array}{l}1.28 \\
1.12\end{array}$ \\
\hline False & .70 & $\begin{array}{l}2.32 \\
2.40\end{array}$ & $\begin{array}{l}1.09 \\
1.36\end{array}$ \\
\hline Unfriendly & .40 & $\begin{array}{l}2.08 \\
2.24\end{array}$ & $\begin{array}{r}.84 \\
1.03\end{array}$ \\
\hline Impolite & .60 & $\begin{array}{l}2.20 \\
2.32\end{array}$ & $\begin{array}{l}1.06 \\
1.29\end{array}$ \\
\hline Kind & .53 & $\begin{array}{l}6.22 \\
5.91\end{array}$ & $\begin{array}{r}.88 \\
1.44\end{array}$ \\
\hline Rude & .52 & $\begin{array}{l}2.30 \\
2.26\end{array}$ & $\begin{array}{l}1.52 \\
1.22\end{array}$ \\
\hline Creative & .56 & $\begin{array}{l}5.55 \\
5.55\end{array}$ & $\begin{array}{l}1.59 \\
1.30\end{array}$ \\
\hline Careless & .58 & $\begin{array}{l}2.88 \\
2.67\end{array}$ & $\begin{array}{l}1.39 \\
1.25\end{array}$ \\
\hline Dangerous & .53 & $\begin{array}{l}2.76 \\
2.40\end{array}$ & $\begin{array}{l}1.39 \\
1.17\end{array}$ \\
\hline Surprised & .47 & $\begin{array}{l}4.65 \\
4.57\end{array}$ & $\begin{array}{r}.86 \\
1.14\end{array}$ \\
\hline Talkative & .51 & $\begin{array}{l}4.42 \\
4.33\end{array}$ & $\begin{array}{l}1.50 \\
1.28\end{array}$ \\
\hline Friendly & .52 & $\begin{array}{l}6.00 \\
6.00\end{array}$ & $\begin{array}{r}1.33 \\
.75\end{array}$ \\
\hline Dirty & .44 & $\begin{array}{l}2.44 \\
2.48\end{array}$ & $\begin{array}{l}1.68 \\
1.75\end{array}$ \\
\hline Firm & .55 & $\begin{array}{l}4.42 \\
4.17\end{array}$ & $\begin{array}{l}1.44 \\
1.34\end{array}$ \\
\hline Brave & .65 & $\begin{array}{l}5.21 \\
5.04\end{array}$ & $\begin{array}{l}1.61 \\
1.62\end{array}$ \\
\hline Practical & .55 & $\begin{array}{l}5.59 \\
5.32\end{array}$ & $\begin{array}{l}1.11 \\
1.10\end{array}$ \\
\hline
\end{tabular}


Studious

Colorful

Believable

Realistic

Weak

Cautious

Dependable
.67

5.25
5.46

4.04

4.29

5.00

5.04

5.30

5.26

.54

2.88

2.52

.40

4.26

4.56

4.20

4.28
1.30

1.35

1.40

1.40

1.15

.99

1.04

1.11

1.27

.85

1.07

1.10

1.65

1.64 
FULI SAMPLE RELIABIITY

Correlation

Jealous

Clever

False

Unfriendly

Impolite

Kind

Rude

Creative

Careless

Dangerous

Surprised

Talkative

Friendly

Dirty

Firm

Brave

Practical

Colorful
.82

.79

.59

.54

.54

.59

.62

.57

.57

.56

.47

.52

.59

.42

.49

.69

.58

2.93
2.69

5.74

5.70

2.30

2.26

2.14

2.19

2.12

2.07

6.29

6.10

2.02

2.00

5.95

5.73

2.86

2.62

2.60

2.19

4.36

4.36

4.26

4.17

5.93

5.95

2. 48

2.48

4.81

4.60

5.67

5.50

5.46

5.31

.66
St. Dev.

1.18

.99

1.18

1.23

1.11

1.26

.95

1.04

1.15

.83
1.23

1.41

1.14

1.38

1.16

1.10

1.11

1.28

1.08

.81

.92

1.29

1.13

1.15

.89

1.42

1.48

1.16

1.16

1.28

1.16

1.01 .99

4.79

1.57

1.41 
Weak

Cautious

Dependable
.52

.42

.64
2.81

2.58

4.37

4.35

5.11

5.11
1.17

.75

.93
1.02

1.70

1.64 
APPENDIX I

PHOTOGRAPHS OF DYADS 


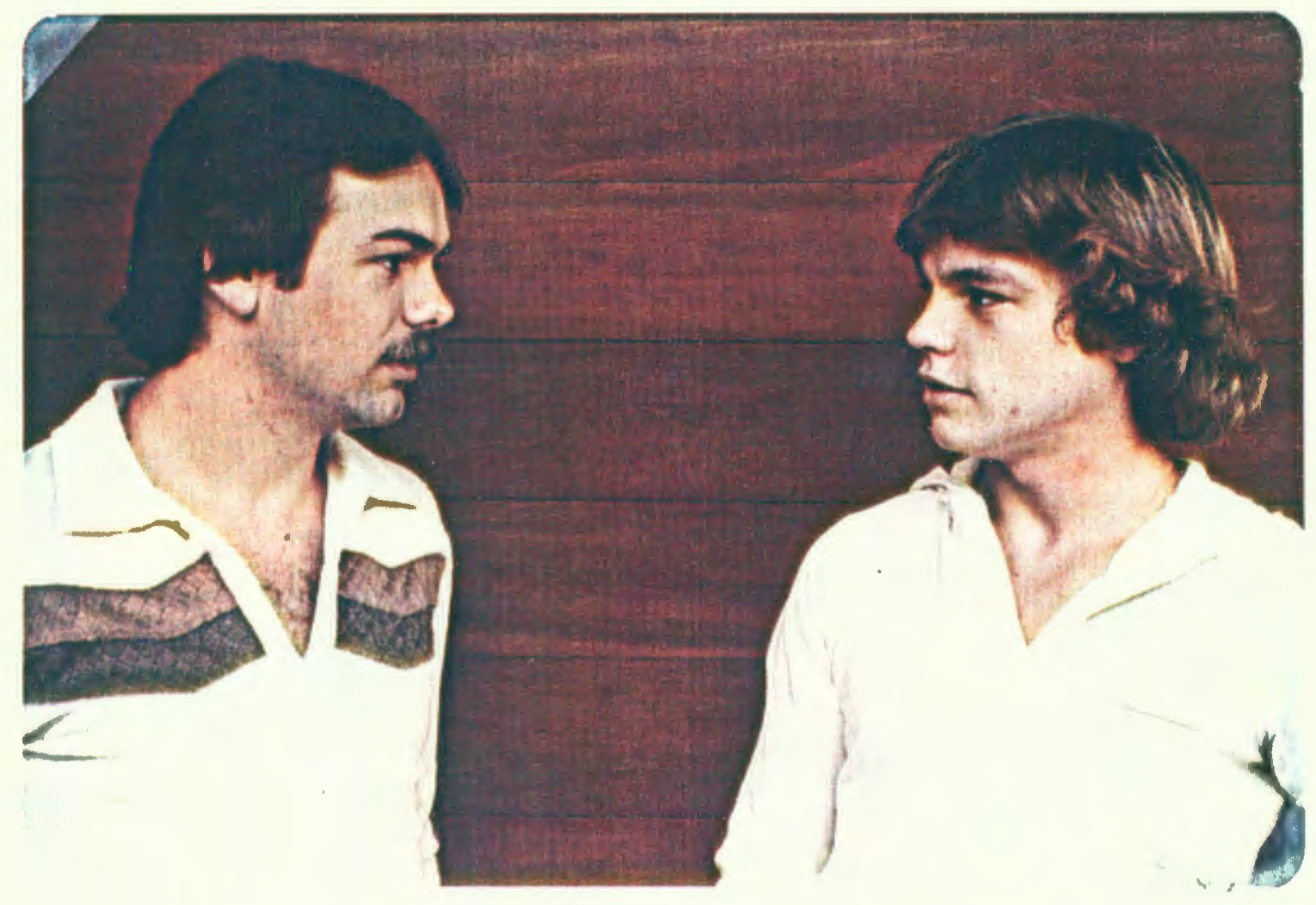

Figure 2. American/American dyad. 


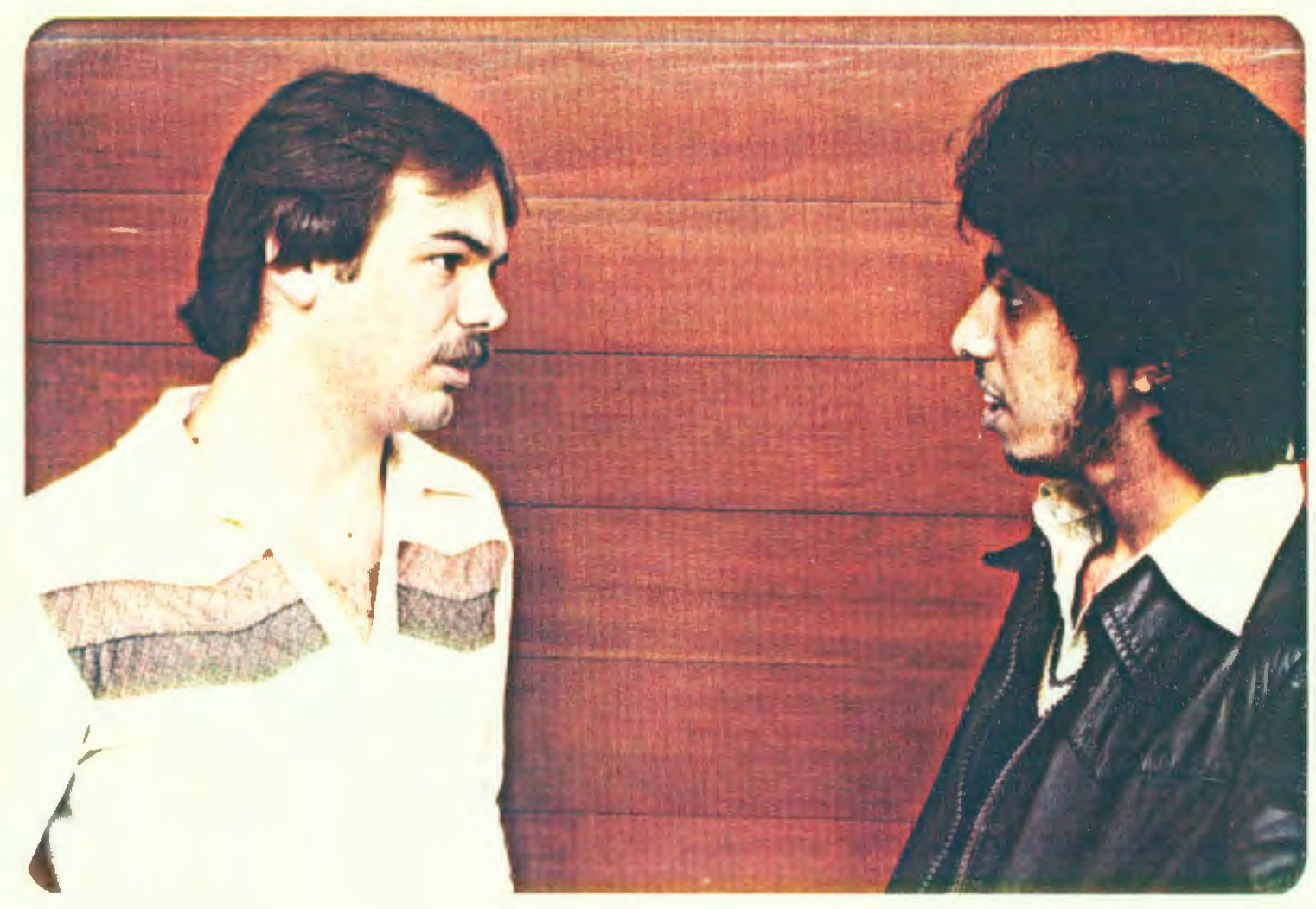

Figure 3. American/Saudi Arabian dyad. 


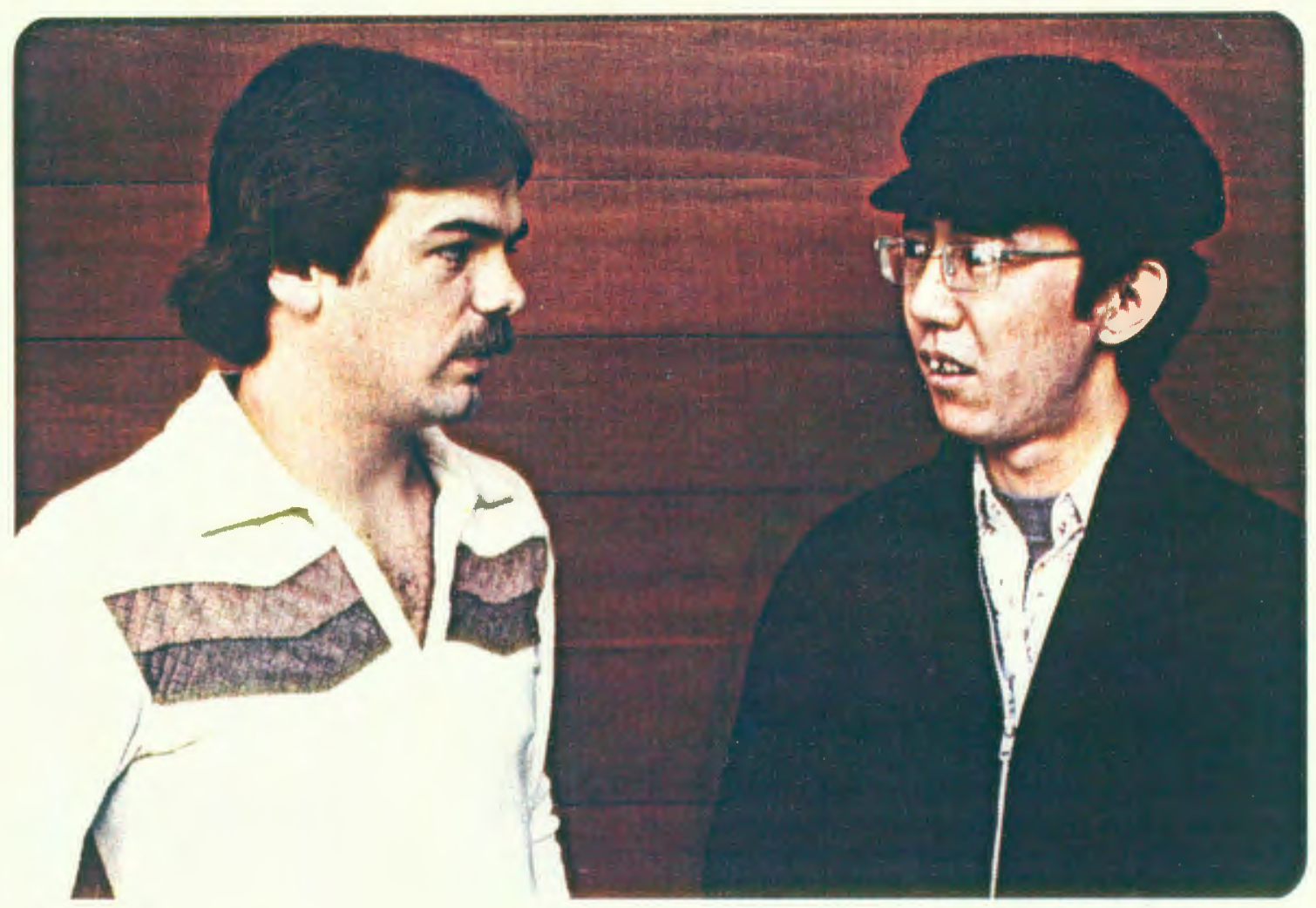

Figure 4. American/Japanese dyad. 


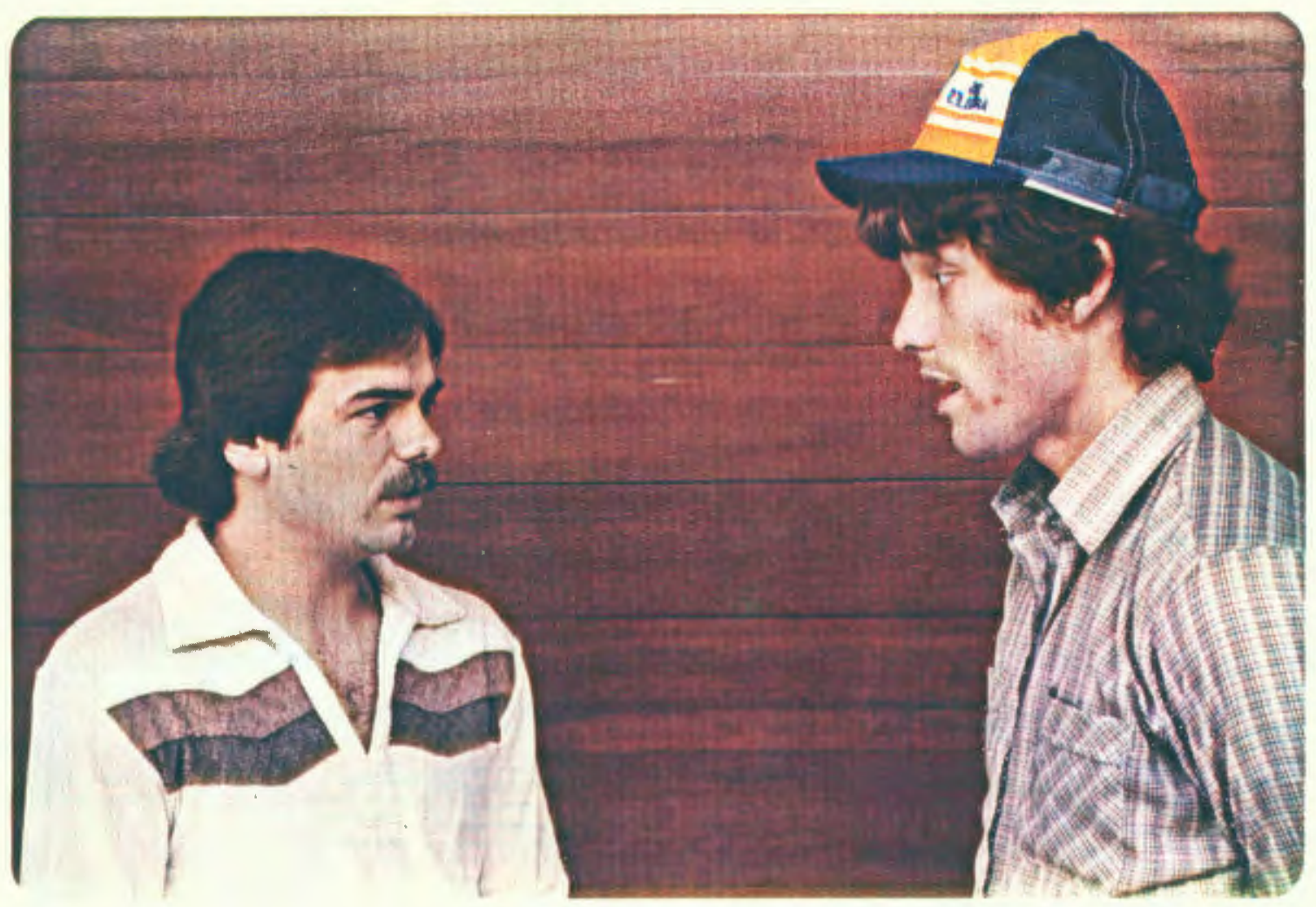

Figure 5. American/American dyad. 


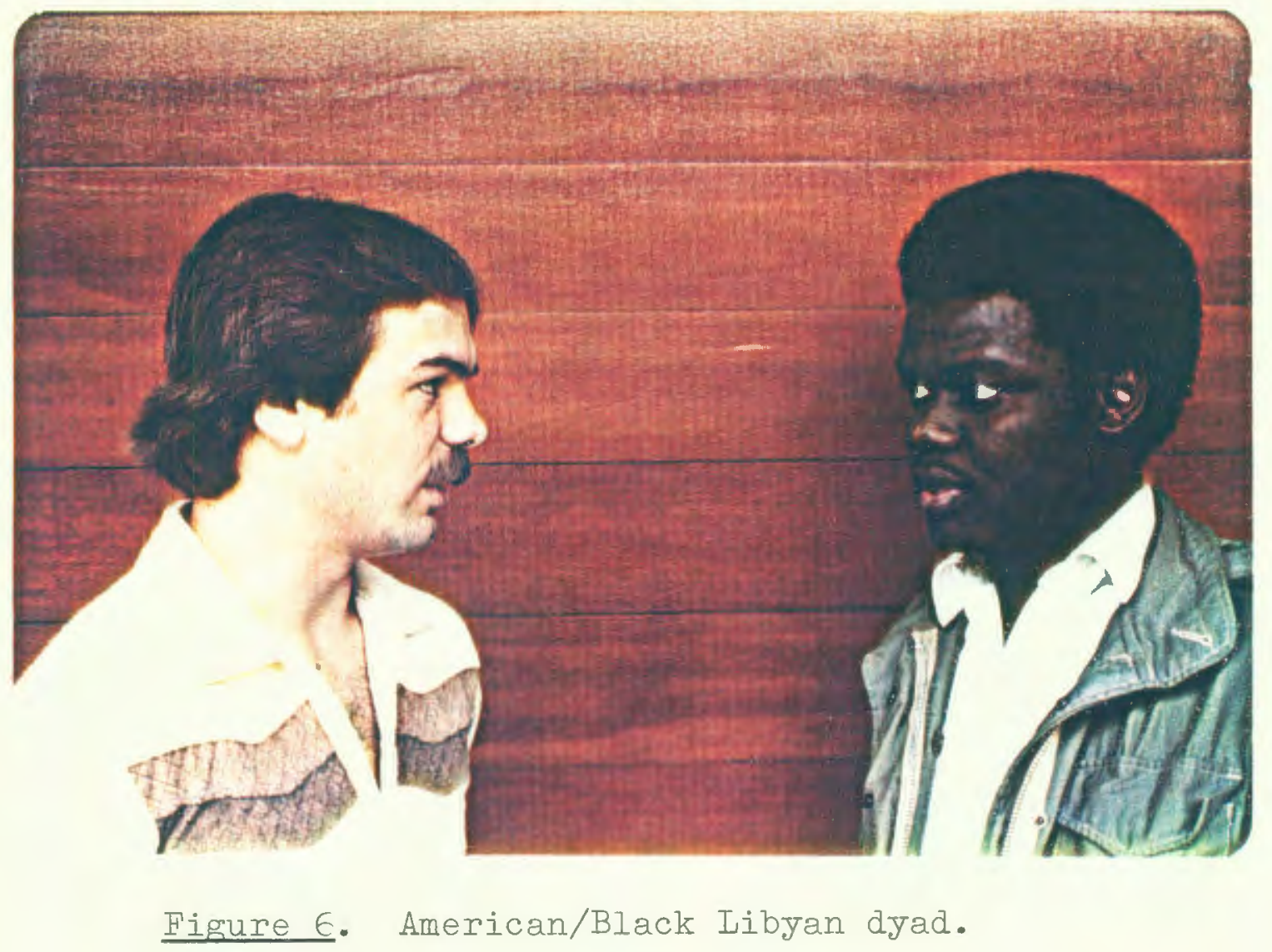


APPENDIX J

REVERSED ORDER OF ADJECTIVE LISTS 
REVERSED ORDER OF ADJECTIVE LISTS

Cautious

Dependable

Weak

Colorful

Practical

Brave

Firm

Dirty

Friendly

Talkative

Surprised

Dangerous

Careless

Creative

Rude

Kind

Impolite

Unfriendly

False

Clever

Jealous 
Talkative

Creative

False

Clever

Firm

Dependable

Friendly

Kind

Surprised

Jealous

Cautious

Rude

Unfriendly

Weak

Dangerous

Brave

Colorful

Careless

Impolite

Dirty

Practical 
Brave

Talkative

Impolite

Colorful

Careless

Friendly

Weak

Clever

Firm

Surprised

Dirty

Rude

False

Jealous

Practical

Cautious

Kind

Creative

Dangerous

Unfriendly

Dependable 
Jealous

Clever

False

Unfriendly

Impolite

Kind

Rude

Creative

Careless

Dangerous

Surprised

Talkative

Friendly

Dirty

Firm

Brave

Practical

Colorful

Weak

Dependable

Cautious 
Dependable

Unfriendly

Dangerous

Creative

Kind

Cautious

Practical

Jealous

False

Rude

Dirty

Surprised

Firm

Clever

Weak

Friendly

Careless

Colorful

Impolite

Talkative

Brave 